\title{
Medicago truncatula IPD3 Is a Member of the Common Symbiotic Signaling Pathway Required for Rhizobial and Mycorrhizal Symbioses
}

\author{
Beatrix Horváth, ${ }^{1}$ Li Huey Yeun, ${ }^{2}$ Ágota Domonkos, ${ }^{1}$ Gábor Halász, ${ }^{1}$ Enrico Gobbato, ${ }^{3}$ Ferhan Ayaydin, ${ }^{4}$ \\ Krisztina Miró, ${ }^{1}$ Sibylle Hirsch, ${ }^{3}$ Jongho Sun, ${ }^{3}$ Million Tadege, ${ }^{5}$ Pascal Ratet, ${ }^{6}$ Kirankumar S. Mysore, ${ }^{5}$ \\ Jean-Michel Ané, ${ }^{2}$ Giles E. D. Oldroyd, ${ }^{3}$ and Péter Kaló ${ }^{1}$
}

${ }^{1}$ Agricultural Biotechnology Center, Gödöllö 2100, Hungary; ${ }^{2}$ Department of Agronomy, University of Wisconsin, 1575 Linden Drive, Madison 53706, U.S.A.; ${ }^{3} J o h n$ Innes Centre, Norwich NR4 7UH, United Kingdom; ${ }^{4}$ Cellular Imaging Laboratory, Biological Research Center, Szeged 6726, Hungary; ${ }^{5}$ Samuel Roberts Noble Foundation, 2510 Sam Noble Parkway, Ardmore, OK 73401, U.S.A.; ${ }^{6}$ Institut des Sciences du Végétal, CNRS, 91198 Gif sur Yvette, France

Submitted 25 January 2011. Accepted 7 June 2011.

Legumes form endosymbiotic associations with nitrogenfixing bacteria and arbuscular mycorrhizal (AM) fungi which facilitate nutrient uptake. Both symbiotic interactions require a molecular signal exchange between the plant and the symbiont, and this involves a conserved symbiosis (Sym) signaling pathway. In order to identify plant genes required for intracellular accommodation of nitrogen-fixing bacteria and AM fungi, we characterized Medicago truncatula symbiotic mutants defective for rhizobial infection of nodule cells and colonization of root cells by AM hyphae. Here, we describe mutants impaired in the interacting protein of DMI3 (IPD3) gene, which has been identified earlier as an interacting partner of the calcium/ calmodulin-dependent protein, a member of the Sym pathway. The ipd3 mutants are impaired in both rhizobial and mycorrhizal colonization and we show that IPD3 is necessary for appropriate Nod-factor-induced gene expression. This indicates that IPD3 is a member of the common Sym pathway. We observed differences in the severity of ipd3 mutants that appear to be the result of the genetic background. This supports the hypothesis that IPD3 function is partially redundant and, thus, additional genetic components must exist that have analogous functions to IPD3. This explains why mutations in an essential component of the Sym pathway have defects at late stages of the symbiotic interactions.

Legumes form nitrogen-fixing symbioses with soil bacteria collectively called rhizobia and, like most plant species, they also establish interactions with arbuscular mycorrhizal (AM) fungi. Both symbioses facilitate the uptake of mineral nutrients. Host plants and their symbionts form specialized structures

Current address for S. Hirsch: VIB, Department of Plant Systems and Biology, B-9052 Ghent, Belgium

Current address for M. Tadege: Department of Plant and Soil Sciences, Oklahoma State University, Stillwater 74078, U.S.A.

Corresponding author: P. Kaló; Telephone: + 36 28-526104; Fax: +36 28526101; E-mail:kalo@abc.hu

* The $\boldsymbol{e}$-Xtra logo stands for "electronic extra" and indicates that three supplementary figures and one supplementary table are published online and that Figure 7 appears in color online. during these interactions: rhizobia induce the development of root nodules on the host plant wherein the reduction of atmospheric nitrogen takes place, while AM fungal hyphae form a densely ramified structure in the inner cortical cells of the root where the transfer of nutrients occurs.

The exchange of diffusible signaling molecules between symbionts and host plant takes place prior to physical contact. The flavonoid and isoflavonoid contents of root exudates activate rhizobia to produce nodulation (Nod) factors (NF), which induce the host plant to initiate nodulation (Oldroyd and Downie 2008; Riley et al. 2006). The perception of NF activates ion fluxes (Felle et al. 1998) and calcium oscillations in the cytoplasm (Ehrhardt et al. 1996), modulates the cytoskeleton (Timmers et al. 1999), and induces early nodulin genes (Catoira et al. 2000; Journet et al. 1994) in root epidermal cells. NF also induce root hair deformations, cortical cell divisions, and the formation of preinfection structures (Oldroyd and Downie 2008). As a signal for mycorrhizal fungi, roots release strigolactones that promote hyphal branching of AM fungi (Akiyama et al. 2005). Physiological and molecular data presumed the existence of fungal factors which elicit responses on the host plant (Kosuta et al. 2003; Kuhn et al. 2010; Navazio et al 2007; Olah et al. 2005), including calcium oscillations and gene expression in root epidermal cells (Kosuta et al 2008). The recent study by Maillet and associates (2011) identified lipochitooligosaccharide molecules acting as the fungal signaling factor. The structural similarity of these mycorrhizal factors with NF further supports the idea that the root nodule symbiosis recruited the components of the ancient developmental program of AM symbiosis (Parniske 2008).

Both rhizobia and mycorrhizal fungi exist as intracellular symbionts, which requires the coordinated development of both partners to allow invasion and appropriate differentiation (Jones et al. 2007; Oldroyd and Downie 2008; Parniske 2008). The best-characterized rhizobial infection strategy occurs via root hairs. Rhizobia become trapped in root hair curls and induce invaginations from these curled root hairs, forming tubular structures called infection threads (IT). The IT grows toward the newly divided cells of the developing nodule primordial, wherein the bacteria are released and colonize the host cells through endocytosis. The bacteria become enveloped with a plant-derived peribacteroid membrane, forming a cytoplasmic structure referred to as the symbiosome. In the symbiosomes, the bacteria undergo morphological changes and metabolic dif- 
ferentiation to transform into their symbiotic state, termed bacteroids. The symbiosome is the site of nitrogen fixation and functions in nutrient and signal exchange between the plant and the bacteroid (Lodwig and Poole 2003). Signal exchanges and the contact of AM hyphae with the root also induce morphogenetic changes in the partners. Upon contact with the root, the hyphae swell to develop the hyphopodium, a penetration apparatus that facilitates the invasion of epidermal cells (Lima et al. 2009; Parniske 2004; Smith et al. 2006). AM fungal hyphae cross the epidermis through intracellular invasion and traverse the outer cortex by intercellular invasion, before penetrating inner cortical cells wherein highly branched hyphal structures, the arbuscules, are formed. The arbuscules function as an interface to facilitate nutrient exchange between the fungus and the host plant.

Genetic dissection of nodulation in the model legumes Medicago truncatula and Lotus japonicus has identified many of the components of the NF-signaling pathway. This analysis revealed that several plant genes are required for both the bacterial and fungal symbioses and, thus, both symbiotic interactions share common signaling components (the common Sym pathway). In the legume-rhizobia symbiotic model systems, ion channel proteins DMI1 (Ané et al. 2004) and CASTOR and POLLUX (Imaizumi-Anraku et al. 2005); nucleoporins NUP85, NUP133, and NENA (Groth et al. 2010; Kanamori et al. 2006; Saito et al. 2007); and a membrane-anchored leucinerich repeat receptor-like kinase, DMI2/NORK/SYMRK (Endre et al. 2002; Stracke et al. 2002) are essential for the induction of calcium spiking (Wais et al. 2000). A calcium/calmodulindependent protein kinase (CCaMK) (DMI3) (Lévy et al. 2004; Mitra et al. 2004) functions downstream of calcium spiking and $\mathrm{CCaMK}$ is postulated to decode and transmit the calcium signal (Oldroyd and Downie 2006). The Sym pathway is required throughout the process of rhizobial invasion and symbiosome formation (Capoen et al. 2005; Godfroy et al. 2006; Limpens et al. 2005).

The formation of fully effective symbiotic nodules requires coordinated regulation between the processes of rhizobial infection initiated in epidermal cells and nodule organogenesis induced in the root cortex (Oldroyd and Downie 2008). Gain-offunction alleles of $C C A M K$ induce spontaneous nodulation in the absence of either rhizobia or NF (Gleason et al. 2006; Tirichine et al 2006), indicating that activation of CCaMK is sufficient for nodulation signaling. In addition to $C C a M K$, a gain-of function allele of the cytokine receptor gene ( $L H K 1)$ (Tirichine et al 2007) is also able to active nodule organogenesis in the absence of rhizobia. The functional hierarchy of symbiotic plant genes in coordinating nodule formation and infection was defined on the basis of spontaneous nodulation and infection phenotypes using these gain-of-function mutants (Hayashi et al. 2010; Madsen et al. 2010). The functional analysis revealed the central regulatory position of CCaMK in connecting the infection and organogenetic pathways in $L$. japonicus. In addition, it was also demonstrated that the components of the common Sym pathway upstream of calcium spiking are only required for activation of CCaMK.

CCaMK interacts with the interacting protein of DMI3 (IPD3) (Messinese et al. 2007) and, like CCaMK (Kaló et al. 2005), IPD3 was localized to the nucleus. The ortholog of $M$. truncatula IPD3 has been identified recently in L. japonicus (Yano et al. 2008) and the analysis of cyclops mutants demonstrated the function of CYCLOPS in invasion and accommodation of both rhizobial and fungal symbiotic partners. The failure of IT growth and the absence of rhizobial infection on spontaneous nodules developed on L. japonicus cyclops roots suggested the importance of CYCLOPS in the CCaMK-mediated cross talk between the IT and the nodule developmental pathways (Hayashi et al. 2010; Madsen et al. 2010).
The functional analysis of IPD3 was not feasible until now because of the lack of available ipd 3 mutants. In this article, we report the identification of mutant alleles of IPD3 and demonstrate that IPD3 is required for IT growth and the invasion of nodules by rhizobia. IPD3 is also indispensable for arbuscule formation in AM symbiosis. Based on the mutant phenotypes, the detected physical interaction between IPD3 and CCaMK, and the requirement of IPD3 for proper induction of early nodulin gene expression, we conclude that IPD3 is a member of the common symbiotic signaling pathway and is necessary for the invasion of the host cell by both rhizobial and fungal symbiotic partners.

\section{RESULTS}

\section{A novel M. truncatula allele required for rhizobial infection.}

Fast-neutron mutagenized $M$. truncatula Jemalong plants were screened for mutant plants ineffective in nodulation (Marsh et al. 2007). From this screen, we identified a mutant that showed symptoms of nitrogen starvation (yellowish leaves and a stunted growth habit) and developed small white nodules on roots, indicating the absence of leghemoglobin (Fig. 1A and $\mathrm{K}$ to $\mathrm{M}$ ). Acetylene reduction assays in mutant nodules showed the complete absence of nitrogenase activity (data not shown). A significant increase in nodule number was detected in the mutant compared with wild-type plants following 6 weeks of inoculation with Sinorhizobium meliloti (Supplementary Fig. $\mathrm{S} 1$ ). For reasons described below, we called the responsible locus IPD3, with this mutant allele referred to as ipd3-1.

The kinetics of nodule development and bacterial infection were analyzed in wild-type and ipd3-1 plants using $S$. meliloti 1021 (pXLGD4), which constitutively expresses the lacZ gene. The ipd3-1 plants showed delayed nodule development and delayed and defective bacterial infection (Fig. 1B, D, and F). No evident difference was observed in root length, number of rhizobial microcolonies, and nodule primordia per root length (data not shown) between wild-type plants and ipd3-1 at 5 or 10 days following inoculation. The number of growing IT in root hairs per measure of root length was higher in ipd3-1 mutants (1.9 \pm 0.8 ; mean \pm standard deviation [SD]) than in wildtype plants $(0.5 \pm 0.45) 3$ days postinoculation (dpi). The ipd31 mutant showed an extended infected region of the root: $5.6 \pm$ $1.8 \mathrm{~cm}$ for wild-type roots and $8.7 \pm 1.3$ for ipd3-1 (mean \pm SD) $10 \mathrm{dpi}$. After four or more weeks, two types of white nodules developed on mutant plants; most nodules were small and round in shape (Fig. 1L) and these nodules often showed abnormal morphology at the nodule apex, with IT limited to this region (Fig. 1F). A small number of nodules developed into elongated cylindrical structures (Fig. 1M) but without the characteristic zonation of indeterminate nodules. Behind the meristematic region, these nodules contained an extended invasion zone with hypertrophied IT and a narrow zone of cells at the base of the nodules which were not penetrated by IT (Fig. 1H). The frequency of these elongated nodules varied between experiments and individuals but generally was between 5 and $10 \%$ of all nodules.

To further investigate the progression of the infection process in the elongated nodules of ipd3-1, we used the nucleic acid-binding dye SYTO13 that reveals plant cell nuclei and bacteria (Haynes et al. 2004). Nodules on wild-type plants showed cells largely occupied by bacteria (Fig. 2A). In contrast, only plant nuclei fluoresced in the cells in the basal part of the ipd3-1 elongated-type nodules (Fig. 1H), indicating that these cells were not invaded by rhizobia (Fig. 2B). The images taken at the boundary of the enlarged invasion zone and the basal part of ipd3-1 nodules showed cells with fluorescent 
plant nuclei and branched IT (Fig. 2C), with bacteria retained inside of the IT (Fig. 2D). Most IT displayed an abnormal morphology; they were thick and highly crooked with enlarged, blister-like formations (Fig. 2D) when compared with wild-type ones. Ultrathin sections in the nitrogen fixation zone of wild-type nodules and especially the central region of elongated-type mutant nodules were analyzed using transmission electron microscopy. Wild-type nodule cells were fully packed with bacteroids (Fig. 2E) whereas cells in ipd3 nodules were devoid of bacteroids (Fig. 2F). IT in ipd3-1 showed unusually thick layers between the lumen and the plant cell walls and tortuous plasma membrane (Fig. $2 \mathrm{H}$ ) which were never observed in wild-type ones. From these analyses, we conclude that the major function of IPD3 is to promote appropriate IT growth.

\section{Positional cloning identifies IPD3.}

A map-based cloning approach was used to identify the gene affected in the ipd 3 mutant. The segregation ratio of the symbiotic phenotype in the backcrossed (40 Fix+/13 Fix-) and mapping populations (323 Fix+/135 Fix-) indicated that the mutant phenotype was inherited as a single recessive locus $\left(\chi^{2}=0.062\right.$ and probabilities $[P]$ between 0.975 and 0.9 in the backcrossed population and $\chi^{2}=4.89$ and $P=0.025$ to 0.05 in the F2 population). Initially, the mutant locus was positioned on the upper arm of chromosome 5 (LG 5) between markers MtB108 and MtB93 (Mun et al. 2006). Fine mapping positioned the locus in the genomic region covered by BAC clones mth4-3n15 (accession number CU914135) and mth4-28c15 (CU469555) (Supplementary Fig. S2A). Introntargeted markers were designed based on predicted coding sequences on these two BAC clones, and genetic markers generated for the Golgi transport-related protein $(G T P)$ and the BREVIS RADIX-like (BRL) genes identified a genomic region of $152 \mathrm{~kb}$ that contained the locus. Oligonucleotide primers were synthesized for the seven predicted genes in the region and polymerase chain reactions (PCR) were performed to amplify genomic DNA and cDNA samples prepared from the mutant plant.

The amplification of a part of the IPD3 gene detected a deletion in the IPD3 transcript. Sequence analysis of the IPD3
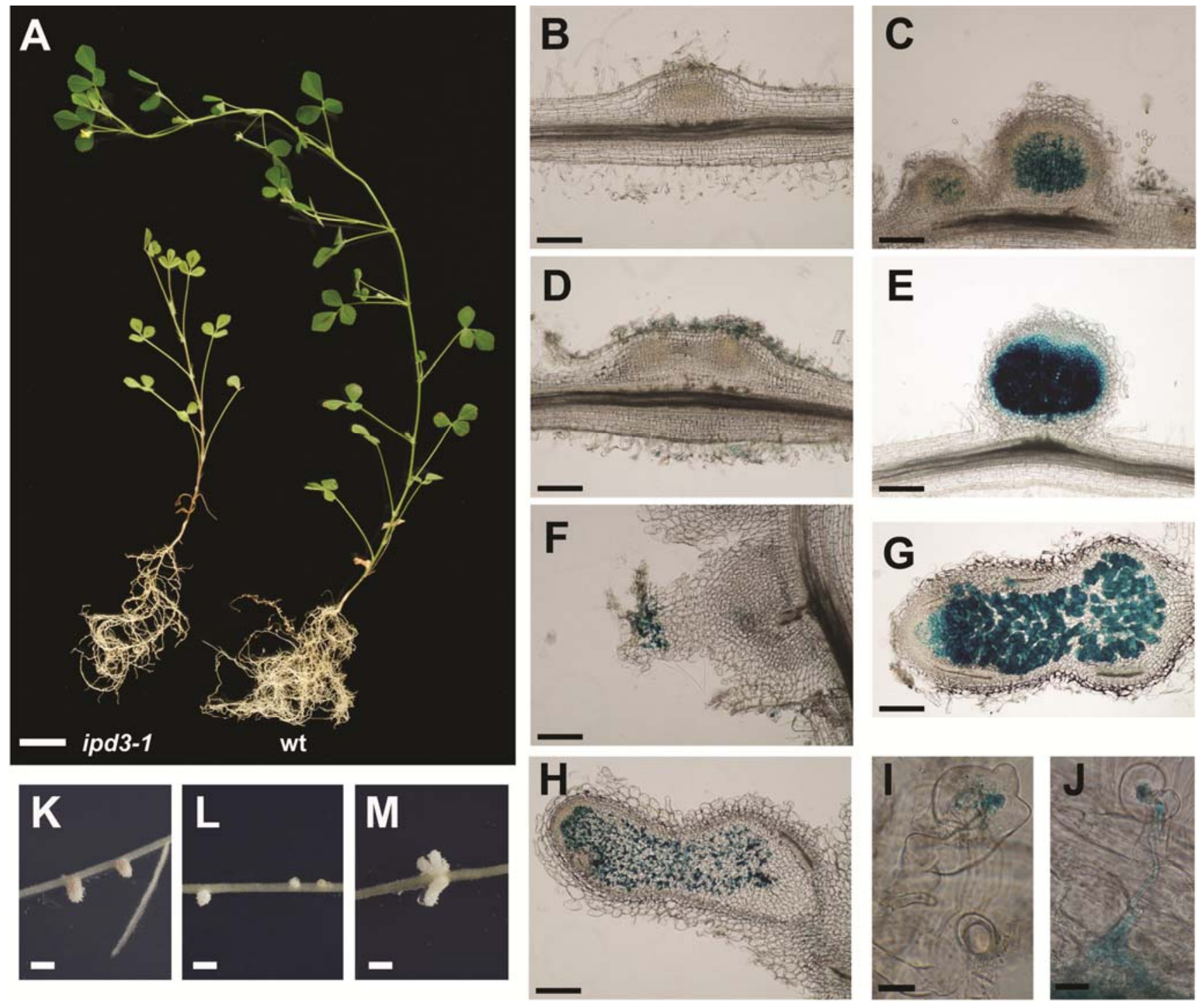

Fig. 1. Nodulation phenotypes of ipd3-1 and wild-type plants. A, The ipd3-1 mutant showed stunted growth compared with the wild type following 6 weeks of inoculation with Sinorhizobium meliloti strain. Kinetics of nodule development in $\mathbf{B}, \mathbf{D}, \mathbf{F}$, and $\mathbf{H}$, ipd3-1 and $\mathbf{C}$, E, and $\mathbf{G}$, wild-type plants inoculated with $S$. meliloti expressing the lacZ gene. Nodule sections ( $60 \mu \mathrm{m}$ thick) were prepared with a vibration microtome and stained with X-gal at 5 (B and C), 10 (D and $\mathrm{E}$ ), and 21 (F and $\mathrm{G}$ ) days postinoculation (dpi). $\mathbf{I}$, ipd3-1 and $\mathbf{J}$, wild-type root hairs with infection threads. The infection thread in ipd3-1 is delayed in development compared with the wild type. $\mathbf{H}$, Light micrograph of an X-gal-stained elongated-type mutant nodule 4 weeks postinoculation. K, Pink nodules developed on wild-type root following 4 weeks of inoculation. $\mathbf{L}$ and $\mathbf{M}$, Two types of white nodules, small spherical (L) and elongated (M), were formed on ipd3-1 roots. Scale bars: $2 \mathrm{~cm}$ in A, $200 \mu \mathrm{m}$ in B to H, and $2 \mathrm{~mm}$ in $\mathrm{K}$ to M. Bars in the images of I and $\mathrm{J}=20 \mu \mathrm{m}$. 
cDNA revealed that the entire fourth exon of IPD3 was missing in the ipd3-1 mutant. A single base-pair change and a 6-bp deletion at the junction of the fourth exon and fourth intron in IPD3 caused imperfect splicing and a transcript lacking exon 4 (Fig. $3 \mathrm{~A})$. The deletion of the fourth exon of the IPD3 transcript generates a frameshift and a premature translational termination in exon 5 and, thus, the mutant transcript encodes a truncated protein with eight additional non-IPD3-specific residues following the third exon. The predicted incomplete gene product lacks the terminal nuclear localization signal and a region determined to be sufficient for the interaction with CCaMK (Messinese et al. 2007).

\section{Novel mutant allele of IPD3.}

To validate the genetic identity of IPD3, we identified another ipd3 allele (NF5939) from the Tnt1-insertional population of M. truncatula (Tadege et al. 2008). PCR-amplified fragments were sequenced to identify the exact insertion site of the 5.3-kb Tnt1 retrotransposon in the NF5939 line (Fig. $3 \mathrm{~A})$ and this was used to generate homozygous mutant lines. F1 plants from a cross of ipd3-1 and NF5939 were all Fix- ( $n$ $=4$ ), indicating that they belong to the same complementation group; therefore, NF5939 is hereafter termed ipd3-2. Mutant and wild-type roots were inoculated with S. meliloti 1021 (pXLGD4) to analyze the function of IPD3 in root-nodule symbiosis. On wild-type roots, IT and fully developed nodules were observed (Fig. 3B and D). Nodule-like structures were developed on mutant roots (Fig. 3C), suggesting the induction of cortical cell divisions. Although ipd3-2 mutants displayed root hair deformations, no IT growth was observed in the presence of rhizobia (Figs. 3C and 2E), indicating defects in IT development in the ipd3-2 mutant.

\section{Genetic complementation of ipd3 mutants.}

In order to further prove that the mutation in IPD3 caused the mutant phenotypes, we carried out genetic complementation experiments. The open reading frame of IPD3 was fused either to the native IPD3 or $35 \mathrm{~S}$ promoters and introduced into ipd3-1 and ipd3-2 roots using Agrobacterium rhizogenes-mediated hairy root transformation. The roots were inoculated with S. meliloti 1021 (pXLGD4). Transformed roots were detected by either the green fluorescent protein (GFP) or DsRed fluorescent markers. Because rhizobia induce noninvaded nodules in the ipd3-1 mutant, we assessed the infection of the nodules on the transformed roots following X-Gal staining. White undeveloped nodules formed on ipd3-1 and ip3-2 roots transformed either with the empty vector or the $35 S:: I P D 3$, and these nodules lacked the proper zonation of indeterminate nodules with bacteria restricted to IT (Fig. 4A to F), indicative of the mutants. The inactivity of the $35 \mathrm{~S}$ promoter in the nodule tissue was reported by Auriac and Timmers (2007). Therefore, the unsuccessful complementation of ipd 3 mutants with the $35 \mathrm{~S}$ promoter construct suggests the requirement of the proper spatiotemporal expression of IPD3 during nodule development.

The nodules on the roots of ipd3-1 and ipd3-2 mutants transformed with IPD3 driven by its native promoter were pink, suggesting that these were functional nodules (Fig. $4 \mathrm{G}$ and $\mathrm{P}$ ). The nodules showed the zones of typical indeterminate nodules and cells in the infection and the nitrogen fixation zones stained blue, indicating that these cells were invaded by rhizobia (Fig. 4I). S. meliloti CSB357 containing a nifH::uidA fusion (Bright et al. 2005) revealed normal nifH expression in these complemented nodules (Fig. 4R), indicating a full rescue of the mutant phenotype.

IPD3 is closely homologous to L. japonicus CYCLOPS (Yano et al. 2008). However, the ipd3-1 and cyclops mutants are not identical in phenotype. Although only development of nodule primordia and block of mycorrhizal intracellular infection was observed on cyclops mutant, nodule and arbuscule development is more advanced on ipd3-1 roots. To assess whether $C Y C L O P S$ is orthologous to IPD3, we transformed ipd3-1 with L. japonicus CYCLOPS driven by the CYCLOPS native promoter. The nodules on transformed roots showed patterns of $S$. meliloti expressing lac $Z$ activity indicative of wild-type nodules (Fig. 4L) and we could detect bacterial release into the nodule cells, suggesting that L. japonicus $C Y$ CLOPS can complement the ipd3-1 mutant.

\section{IPD3 functions in NF signaling.}

It has been proposed that CYCLOPS functions in the Sym pathway downstream of calcium spiking in a complex with CCaMK/DMI3 (Yano et al. 2008). In a similar fashion, we found that the ipd3-1 mutant showed a pattern of calcium spiking similar in periodicity and upward phase of the spikes to the wild-type plants following NF treatment (Fig. 5A). The proposed position of IPD3/CYCLOPS would place it upstream of NF-induced gene expression. To test this, we crossed the $\mathrm{pENOD} 11:: \beta$-glucuronidase (GUS) reporter (Journet et al. 2001) into the ipd3-1 mutant. In contrast to wild-type plants, ipd3-1 showed a very limited NF induction of $\mathrm{pENOD} 11:: G U S$; activity was restricted to a smaller region than the wild-type and the intensity of GUS staining was always reduced (Fig. 5B). This was further validated using quantitative reverse-transcription (qRT)-PCR that also allowed us to test additional genes (Fig. 5C). A significant reduction of NF-inducible ENOD11 expression was detected following $16 \mathrm{~h}$ of NF treatment in the ipd3-1, ipd3-2 and ipd3-3 (Mtsym1) (Ovchinnikova et al. 2011) alleles. In addition, a lower relative transcript level of NIN and HAP2.1 (Combier et al. 2006) was also detected in the three ipd3 mutants (Fig. 5C). As was demonstrated earlier, DMI2 and NSP2 are required for NF-induced gene expression (Catoira et al. 2000; Oldroyd and Long 2003) and, accordingly, no or reduced induction of ENODI1, HAP2, and NIN was detected in $d m i 2$ and $n s p 2$ mutants (Fig. 5C). LIN is suggested to function specifically in the IT pathway (Kiss et al. 2009) and, accordingly, the induction of genes in the organogenic pathway (ENOD11, HAP2 and NIN) was strongly induced in lin mutant. To examine gene expression during nodule formation and bacterial infection, we monitored the relative transcript levels of these marker genes in wild-type and ipd3 mutant plants after 1,8 , and 14 days of inoculation with $S$. meliloti. We observed reductions in the expression of ENOD11, NIN, and HAP2.1 in both ipd3-1 and ipd3-3 but the nature of this reduction was not consistent across all genes (Fig. 5C).

\section{ipd3 mutant alleles show distinct defects in the interaction with mycorrhizal fungi.}

CCaMK/DMI3 and L. japonicus CYCLOPS are important for mycorrhizal symbiosis; therefore, we assessed wild-type, ipd3, and ccamk colonization by Glomus intraradices. The roots of wild-type plants were highly colonized with intraradical hyphae, arbuscules, and vesicles in inner cortical cells (Fig. 6A, B, and G) and these were completely lacking in ccamk-1. Light microscopy did not show abnormal branching or other clear visible differences in vesicle and arbuscule formation in ipd3-1 mutant roots (Fig. 6C and D). However, quantification of colonizing fungal structures revealed that the frequency of colonization was significantly reduced in the ipd3-1 mutant line compared with wild-type roots (Fig. $6 \mathrm{E})$. The ipd3-2 mutant showed more severe defects in the mycorrhizal interaction than ipd3-1; arbuscules were not observed in mutant roots co-cultivated with $G$. intraradices despite the presence of extraradical and intraradical fungal 
hyphae (Fig. 6I). Brown-pigmented cells were frequently observed on mutant roots, suggesting the production of phenolic compounds (Fig. 6I). Very little brown pigmentation was observed in roots with functional arbuscules or in roots that were not inoculated with fungal spores (Fig. 6F and $\mathrm{H}$ ).

\section{Interaction between IPD3 and CCaMK.}

IPD3 of M. truncatula and its ortholog in L. japonicus CYCLOPS both interacted with CCaMK in yeast two-hybrid systems and in transiently transformed Nicotiana benthamiana leaves (Messinese et al. 2007; Yano et al. 2008). To gain more
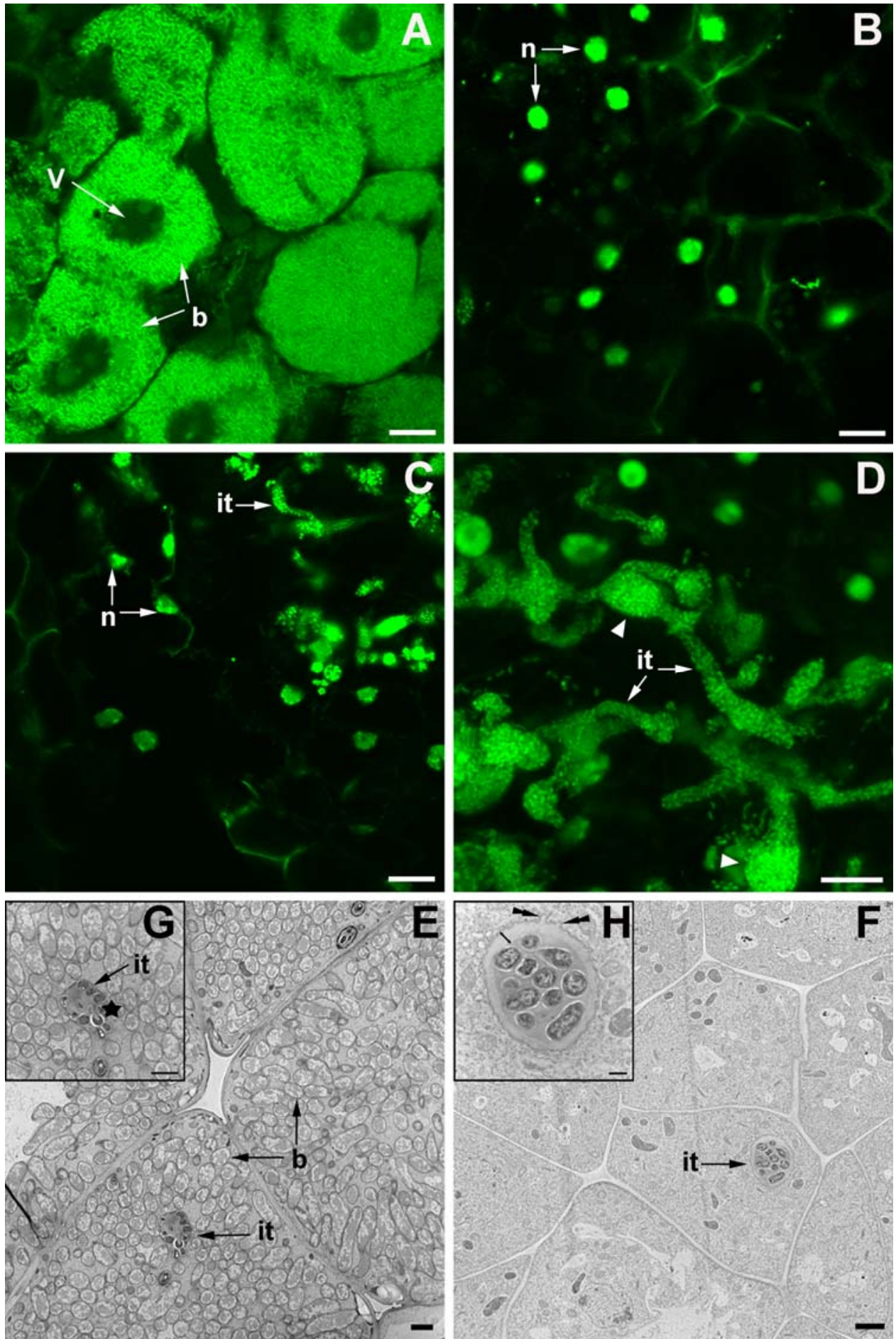

Fig. 2. Bacterial invasion of nodules is impaired in ipd3-1. A, Nodule cells in the nitrogen fixation zone of a wild-type nodule. Most cells are fully occupied with differentiated bacteria. B, Nodule cells in the central part of an ipd3-1 elongated nodule contained no bacteria and only plant nuclei fluoresced in these cells. C, Cells in the boundary of the extended invasion zone and the empty central region of a mutant nodule. Plant nuclei and infection threads with nonreleased, undifferentiated bacteria are visible. D, Higher magnification of infection threads with nonreleased bacteria. Note the abnormal blister-like formations of the infection threads (arrowhead). E, Electron micrograph of cells in the nitrogen fixation zone of a wild-type nodule. Nodule cells were invaded and occupied by differentiated bacteria. F, Cells in the central region of a mutant nodule were not invaded by rhizobia. G, Higher magnification of a cross-section of the infection thread shown in E. The asterisk indicates rhizobia being released. $\mathbf{H}$, Higher magnification of the infection thread with a thickened layer between the lumen of the infection thread and plant cell wall from F (arrow). Double arrowheads indicate the folds of the plasma membrane around the cell wall which was not observed on wild-type infection threads. Scale bars: $10 \mu \mathrm{m}$ in A to D, $2 \mu \mathrm{m}$ in E and F, and $500 \mathrm{~nm}$ in G and H; n = plant nucleus, $\mathrm{v}=$ vacuole, it $=$ infection thread with nonreleased bacteria, and $\mathrm{b}=$ bacteroids. 
insight into the physical interaction between IPD3 and CCaMK, further interaction studies were carried out by yeast two-hybrid systems. The interaction of wild-type or mutated versions of IPD3 and CCaMK were investigated and, as reported earlier, we detected that $M$. truncatula CCaMK fused to either the DNA binding domain (BD) or the activation domain (AD) of GAL4 interacts with IPD3 (Fig. 7). No homodimerization of CCaMK was detected in this system, contrary to previous bimolecular fluorescence complementation (BiFC) studies (Messinese et al. 2007). IPD3 causes autoactivation of the GAL4 system when fused to the GAL4 DNA BD and we were able to delimit the region responsible for this autoactivation between residues 129 and 384 of IPD3 (Supplementary Fig. S3). The interaction between autoactive BD-IPD3 and AD-CCaMK was demonstrated by quantifying the induction of the reporter gene lacZ. IPD3 fused to the DNA-BD of GAL4 showed increased lacZ reporter gene induction when it was co-expressed with AD-CCaMK $(14.85 \pm 0.58 \beta$-galactosidase units; mean \pm standard error [SE] $)$ compared with the combination of BD-IPD3 with empty AD of GAL4 (3.31 $\pm 0.23 \beta$-galactosidase units), indicating interaction of autoactive BD-IPD3 with AD-CCAMK. Yeast growth on histidine-free (LWH) but not on histidine and adenine-free (LWHA) medium revealed a low-affinity protein interaction between IPD3 385 and 513 fused to the BD and full-length IPD3 fused to AD, indicating that the 1-to-384 region of IPD3 promotes homodimerization of IPD3 in yeast (Fig. 7). Autoactive forms of CCaMK were analyzed for their interaction with IPD3. CCaMK T271D, mutated at the putative autophosphorylation site (Gleason et al. 2006), interacted with IPD3. However, the truncated autoactive form of CCaMK (CCaMK 1-311; containing only the kinase domain and lacking the auto-inhibition domain and the three elongation factor hand motifs) was not able to interact with IPD3 (Fig. 7), which indicates that the activated kinase domain of $\mathrm{CCaMK}$ is not sufficient for the interaction with IPD3.

\section{DISCUSSION}

IPD3 was initially identified in an interaction screen with CCaMK/DMI3, a component of the NF signal transduction

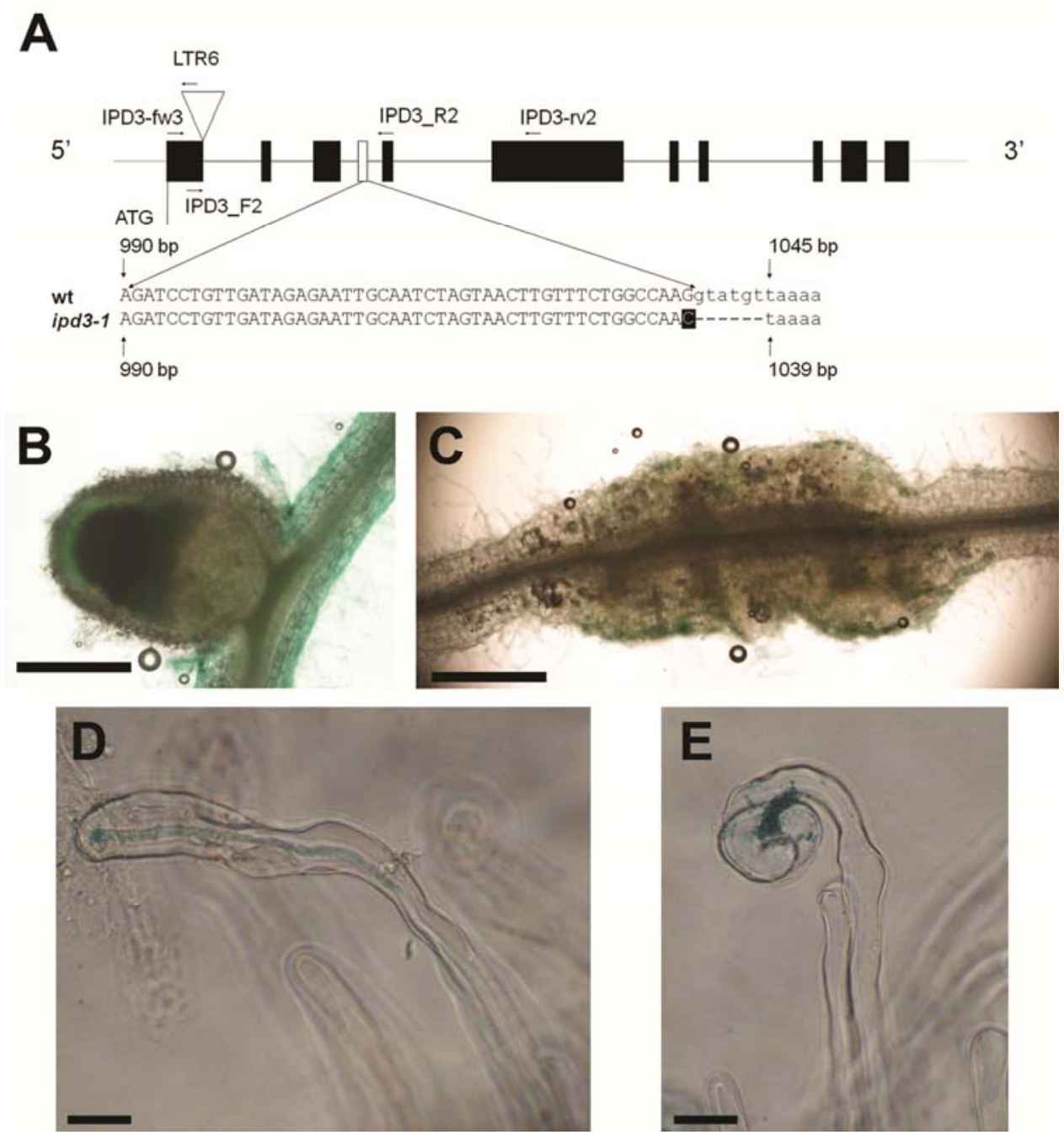

Fig. 3. Nodulation phenotype of the Tnt1 retrotransposon insertion allele of ipd3. A, Gene structure of IPD3 and the position of the Tht1 retrotransposon insertion are shown. Black and open boxes represent exons, lines represent introns, dotted lines represent untranslated regions, and a triangle represents insertion of Tnt1 transposon in ipd3-2. Positions of the oligonucleotide primers used to detect the Tnt1 insertion (IPD3-fw3 and IPD3-rv2) or the deletion (IPD3_F2 and IPD_R2) are indicated by horizontal arrows. Open box shows the fourth exon of IPD3, of which the boundary with the fourth intron contains the mutation in ipd3-1. The wild-type and mutant sequence of the splice site between the fourth exon and intron is shown below; nucleotides in capital letters represent exon region and noncapital letters represent the intron sequence. The G-C nucleotide change in the splice site in the ipd3-1 sequence is highlighted in black and the deleted nucleotides are represented by dashed lines. B to E, Nodulation development is impaired in the Tnt1 transposon insertion mutant ipd3-2. B, Wild-type nodule and C, ipd3-2 nodule. D, Wild-type root hair with an infection thread. E, ipd3-2 with an infection focus within a curled root hair. Scale bars: B and C, $500 \mu \mathrm{m}$; D and E, $20 \mu \mathrm{m}$. 
pathway (Messinese et al. 2007). We report here the identification of ipd3 mutants and the characterization of their symbiotic defects. The nodulation phenotypes of ipd 3 mutants described here and in the accompanying manuscript (Ovchinnikova et al. 2011) indicate that IPD3 functions in IT growth and release of bacteria from IT. Nodule development was severely retarded in ipd3 mutants, with nodule formation blocked at an early primordial stage. Occasionally, we observed more developed nodules in ipd3-1 mutants and not in ipd3-2 mutants but these more-developed nodules never showed bacterial release or
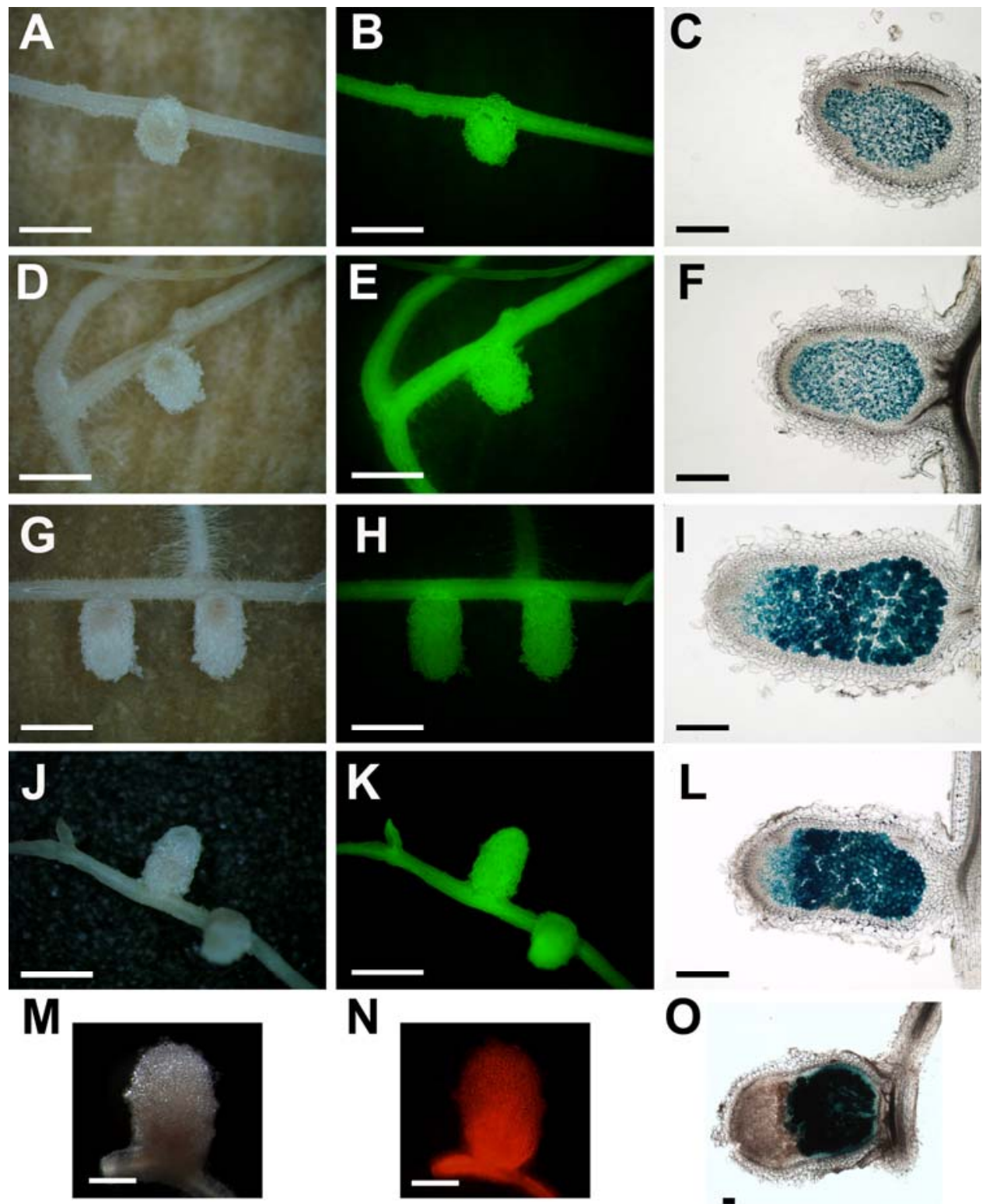

$\mathbf{N}$
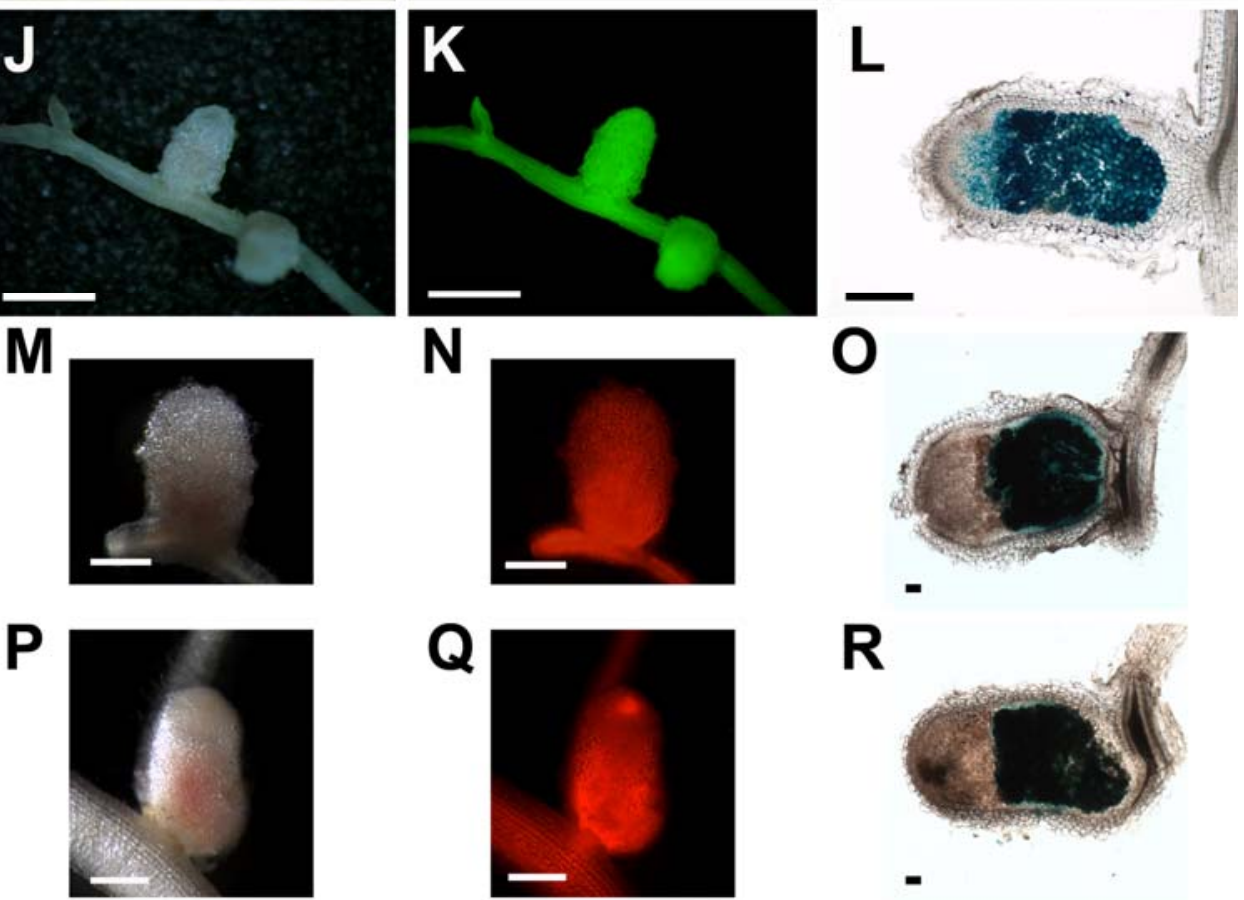

0
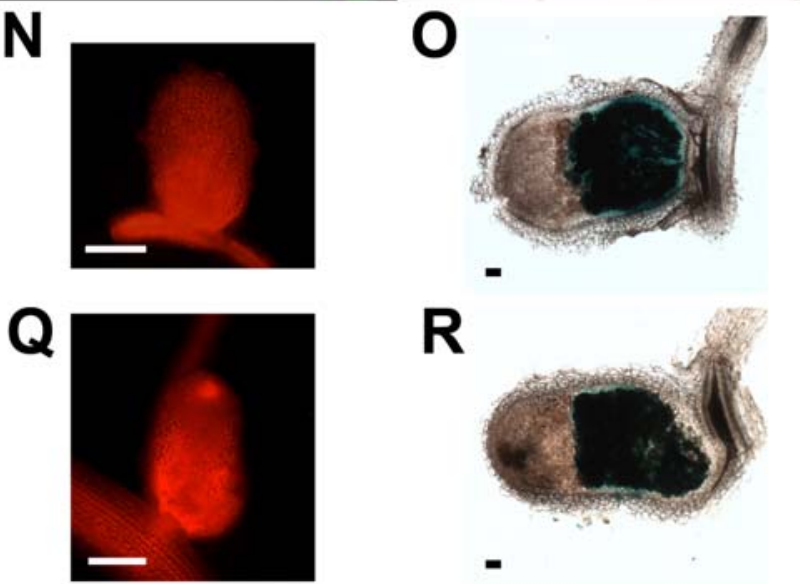

Fig. 4. A to L, IPD3 and CYCLOPS restore the nodulation phenotype of ipd3-1. IPD3 and CYCLOPS genes were introduced into ipd3-1 roots with Agrobacterium rhizogenes and transformed roots were inoculated with Sinorhizobium meliloti 1021 carrying the lacZ gene. Complementation was assessed by the restoration of the typical zonation of the indeterminate nodules characteristic for Medicago truncatula. Transgenic roots were identified by green fluorescent protein fluorescence. Nodules on transgenic roots induced with either $\mathbf{A}$ to $\mathbf{C}$, the empty vector or $\mathbf{D}$ to $\mathbf{F}$, the vector containing the IPD3 coding region driven by the $35 \mathrm{~S}$ constitutive promoter did not show the typical zonation of indeterminate nodules. $\mathbf{G}$ to $\mathbf{I}$, Complementation of the ipd3-1 mutant was carried out with the construct containing $1.23 \mathrm{~kb}$ of the native IPD3 promoter and the open reading frame of IPD3. J to L, Nodules on ipd3-1 roots containing LjCYCLOPS gene showed infected cells in the invasion and nitrogen-fixing zones, indicating the restoration of the nodulation phenotype. M to $\mathbf{R}$, Genetic complementation of ipd3-2 was carried out with the construct containing the same IPD3 insert as used for genetic complementation of ipd3-1. Transgenic roots were identified by DsRed fluorescence. Roots were inoculated with S. meliloti CSB357 (nifH::uidA). M to O, Nodules formed on M. truncatula R108 roots transformed with empty vector; $\mathbf{P}$ to $\mathbf{R}$, nodules on ipd3-2 roots transformed with the pIPD3::IPD3 construct. Scale bar: A, B, D E, G, H, J, and K = 1 $\mathrm{mm} ; \mathrm{M}, \mathrm{N}, \mathrm{P}$, and $\mathrm{Q}=0.5 \mathrm{~mm} ; \mathrm{C}, \mathrm{F}, \mathrm{I}$, and $\mathrm{L}=200 \mu \mathrm{m}$; and $\mathrm{O}$ and $\mathrm{R}=100 \mu \mathrm{m}$. 
symbiosome formation. Early nodulin gene expression was defective in the ipd3 mutants, and this correlates well with the defects we observed in nodule development. The detailed transcriptome analysis of the Mtsyml mutant (the ipd3-3 allele) showed similar defects in gene expression in a recent study by Maunoury and associates (2010), whereby a majority of nod- ule-specific genes were not induced in Mtsym1 but a small number of genes, several of them supposed to function in primordium initiation, were activated at a lower level.

$I P D 3$ is also necessary for the symbiotic association with mycorrhizal fungi, with ipd3 mutants showing reduced fungal colonization. The severity of the mycorrhizal defect appears to

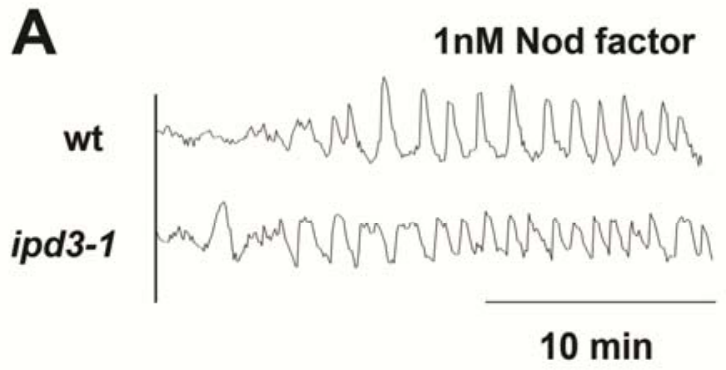

\begin{tabular}{lcc}
\hline & No. Plants & Cells Spiking / Total Cells \\
\hline wt & 3 & $6 / 7$ \\
ipd3-1 & 3 & $6 / 8$ \\
\hline
\end{tabular}
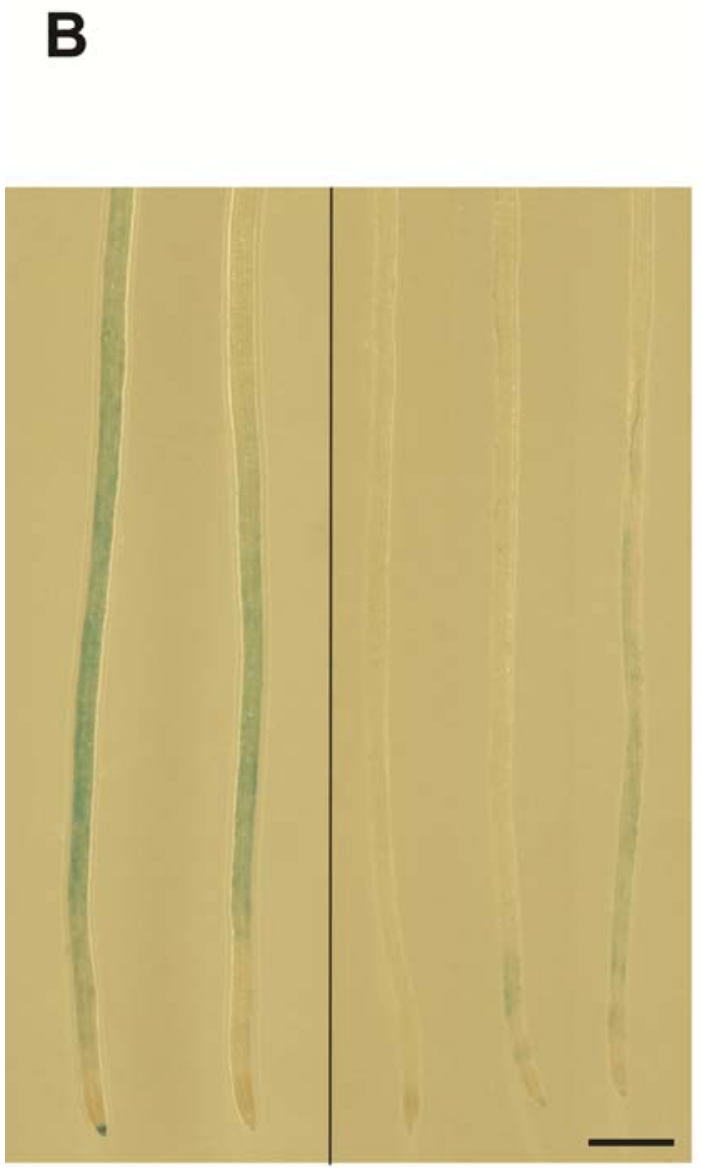

wt
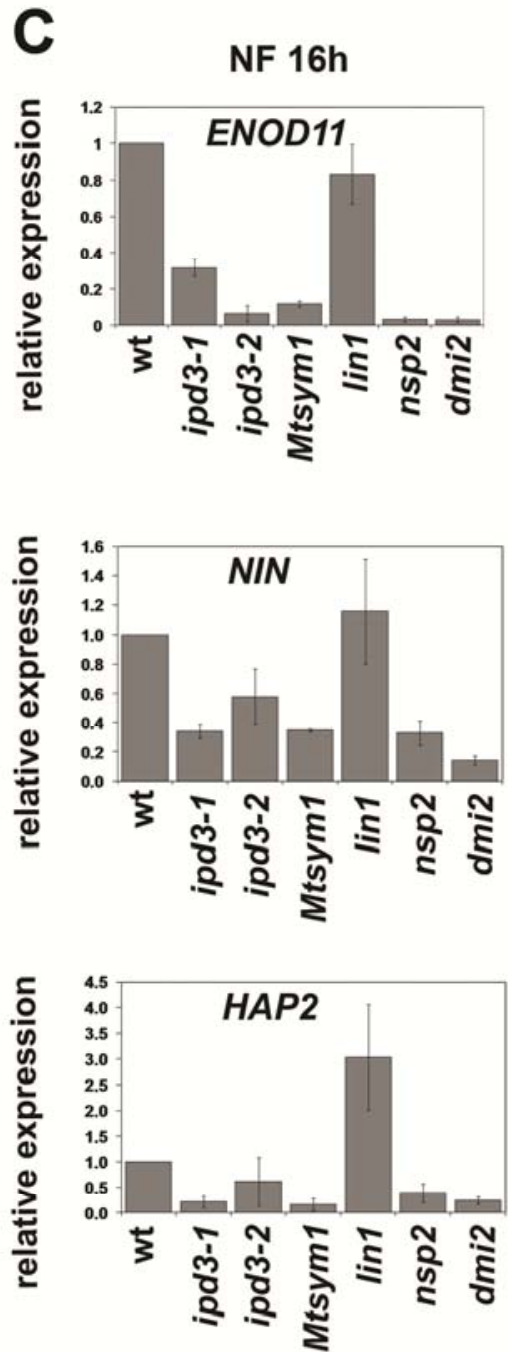

S. meliloti
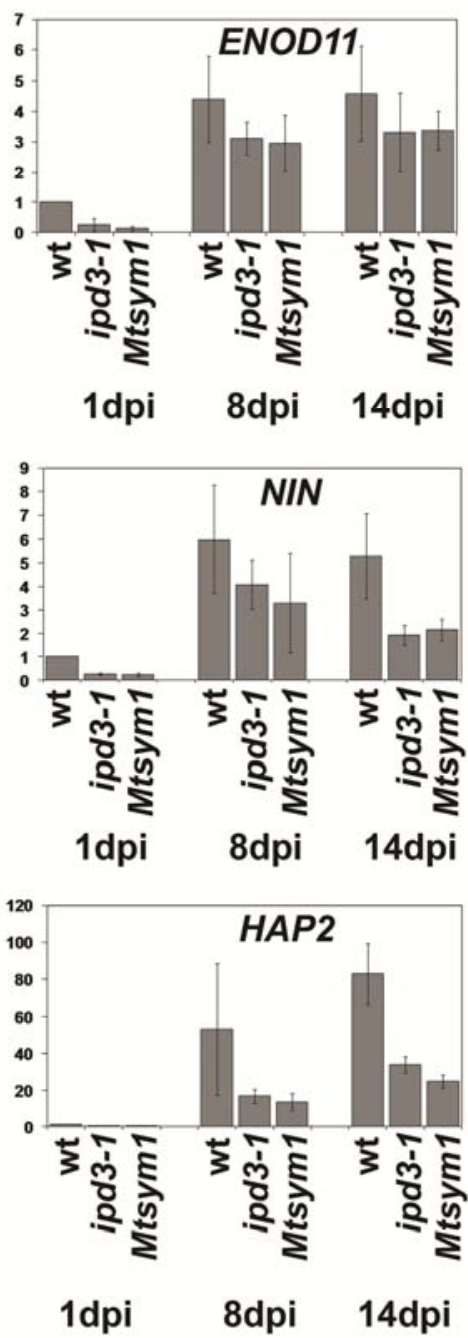

Fig. 5. A, The ipd3-1 mutant shows normal calcium spiking response to Nod factor (NF). The shape and the frequency of calcium spiking traces detected on ipd3-1 root hairs show similar pattern to wild-type root hairs, indicating that the calcium spiking response is intact in ipd3-1 mutant plants. Both traces are from single representative root hairs monitored for $25 \mathrm{~min}$ following the application of $1 \mathrm{nM}$ NF. The inset table summarizes the total number of monitored and responsive root hair cells. B, NF-induced ENOD11:: $\beta$-glucuronidase (GUS) expression is reduced in ipd3-1 mutant. One-week-old wild-type and ipd3-1 mutant plants were continuously treated with $1 \mathrm{nM} \mathrm{NF}$ for $24 \mathrm{~h}$ and afterward stained for GUS activity. Mutant roots showed reduced GUS activity compared with the wild type. Nonsymbiotic GUS activity was detected in both the wild-type and mutant root caps. Scale bar: $1 \mathrm{~mm}$. C, The ipd3 mutants show defects in NF- and rhizobia-induced gene expression. Relative transcript levels of ENOD11, HAP2, and NIN genes in wild-type and mutant plants were calculated in relation to nontreated wild-type plants or 1-day-old inoculated wild-type plants. Values of relative transcript levels are the mean of three to six biological and three technical replicates. Error bars represent standard error; dpi = days postinoculation. 
be dependent on the genetic background in which the ipd $3 \mathrm{mu}$ tation resides: the ipd3-1 allele, that is in a Jemalong background, developed normal internal fungal infection structures, with apparently wild-type arbuscules, although at a reduced frequency. In the accompanying article, Ovchinnikova and associates (2011) report a similar mycorrhizal phenotype in the ipd3-3 allele, also in a Jemalong background. In contrast, the ipd3-2 allele, that is in a R108 (M. truncatula subsp. tricycla) background, shows a complete absence of arbuscules and the accumulation of phenolic compounds. From the analysis of both ecotypes, we interpret that IPD3 is necessary to facilitate fungal colonization, particularly the invasion of inner cortical cells to form arbuscules.

Our analysis reveals that IPD3 is orthologous to L. japonicus CYCLOPS. Despite this orthology, we see differences in the severity of the mutant phenotypes between cyclops and ipd3-1: nodulation is more developed in ipd3-1 and mycorrhizal fungi are able to colonize ipd3-1, leading to arbuscule formation. These differences are unlikely to be the result of subtleties of mutant allele action, because ipd3-1 and ipd3-3 show very similar mutant phenotypes (Bénaben et al. 1995) and both are likely to be null mutants. This is also not the result of subtleties in protein action between IPD3 and CYCLOPS because CYCLOPS can complement ipd3-1. The ipd3-2 mutation is more analogous to cyclops mutants: both show severe defects in rhizobial infection and nodule formation and both show an absence of arbuscule development. This implies that the genetic background in which the ipd3/cyclops mutation resides dictates the severity of the mutant phenotype. Thus, genetic components present in $M$. truncatula subsp. truncatula Jemalong (where ipd3-1 and ipd3-3 reside) can partially compensate for the absence of IPD3 and these components are less active or absent in M. truncatula subsp. tricycla R108 and $L$. japonicus.

IPD3/CYCLOPS functions in symbiosis signaling downstream of calcium spiking but upstream of NF induced gene expression, at an analogous position to $\mathrm{CCaMK}$. It was previ-

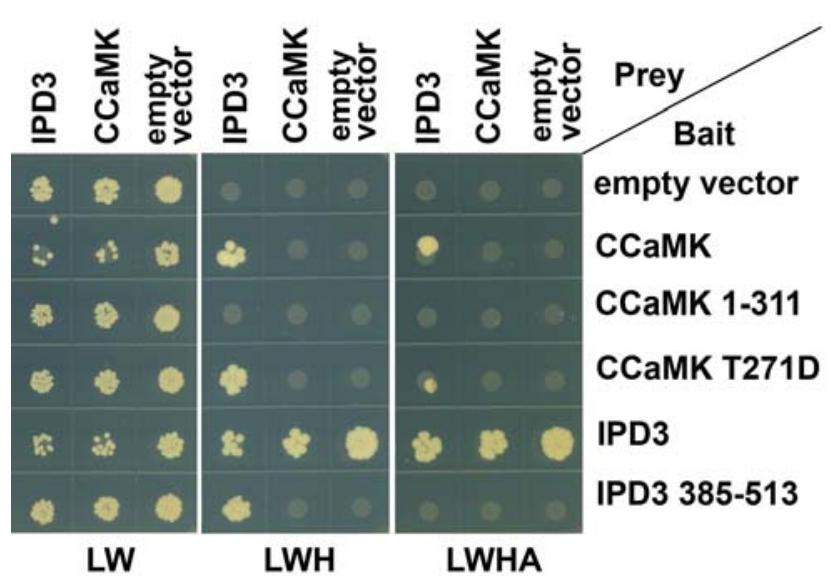

Fig. 7. Dissection of IPD3-calcium/calmodulin-dependent protein kinase (CCaMK) interactions using yeast two-hybrid analysis. CCaMK interacts with IPD3 but not with itself. The kinase domain of CCaMK alone does not interact with IPD3 but the constitutively active CCaMK-T271D mutant does. BD-IPD3 auto-activates the yeast-two-hybrid system and the autoactivating region was mapped by serial deletions. BD-IPD3 385-513 does not auto-activate the system and retains interaction with IPD3 but not with CCaMK. $\mathrm{AD}=$ activation domain of GAL4; $\mathrm{BD}=$ binding domain of GAL4. Selection media were LW, Leu- Trp-; LWH, Leu- Trp- His-; and LWHA, Leu- Trp- His- Ade-.

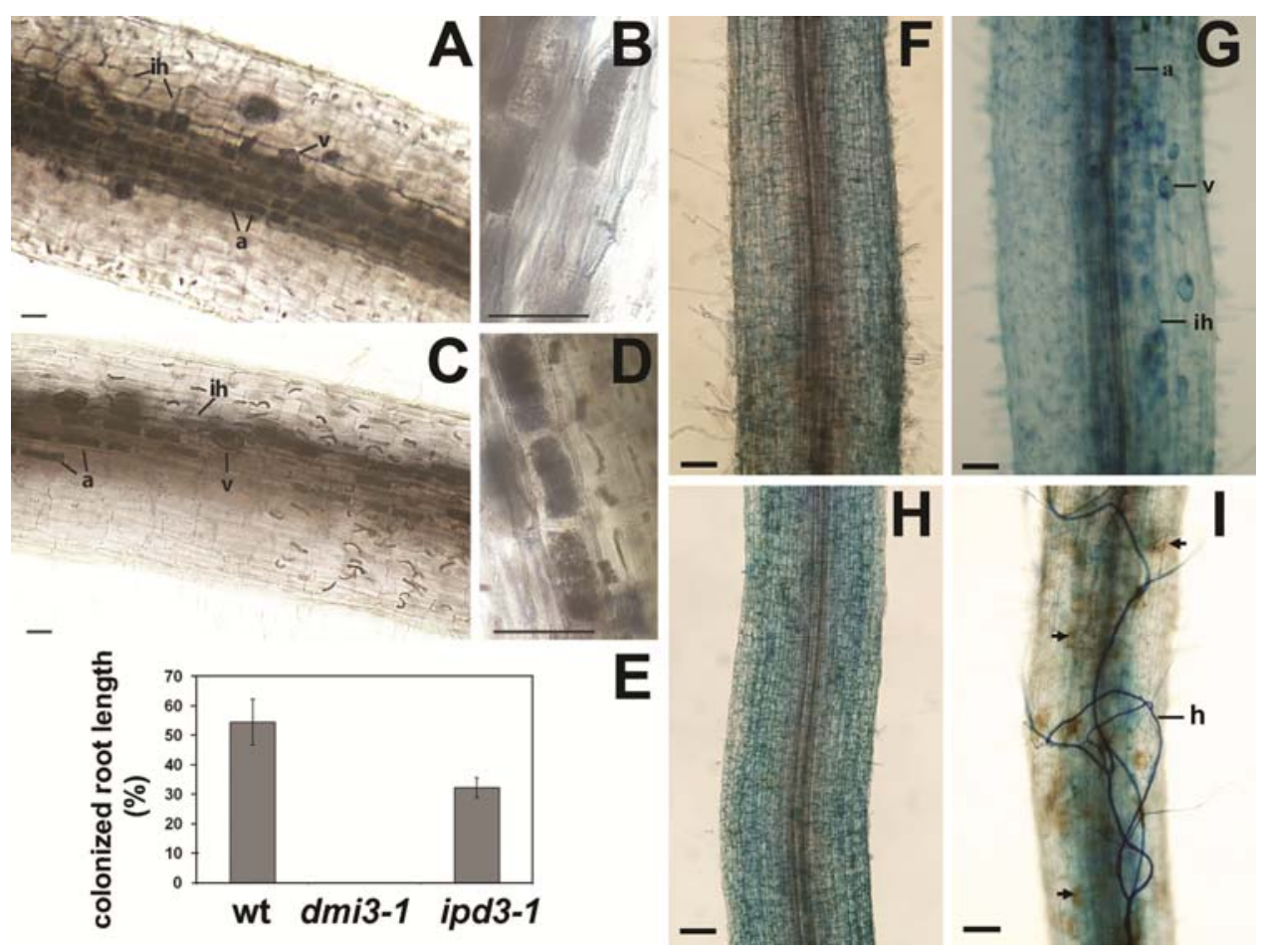

Fig. 6. Arbuscular mycorrhizal (AM) colonization of roots shows distinct defects in ipd3 mutant plants. A to D, Two-day-old wild-type and ipd3-1 seedlings were inoculated with purified Glomus intraradices spores. Root samples were stained with ink 6 weeks after inoculation to investigate colonization levels. Ink-stained fungal structures are shown for $\mathbf{A}$ and $\mathbf{B}$, wild-type and $\mathbf{C}$ and $\mathbf{D}$, ipd3-1 plants. D, The ipd3-1 plants displayed normal arbuscule development, as shown in the higher magnification images on the right. E, AM colonization levels in wild-type (wt) and ipd3-1 plants. As a negative control for mycorrhization, the calcium/calmodulin-dependent protein kinase (ccamk) (dmi3-1) mutant was included. Error bars represent standard errors. F to I, The ipd3-2 mutant showed more severe defects in establishing AM symbiosis; G, arbuscules, intraradical hyphae, and vesicles developed on wild-type plants. I, The ipd3-2 roots inoculated with AM, showing the presence of intraradical and extraradical hyphae and pigmented cells (arrows) but no arbuscules. Images of noninoculated root sections with AM for $\mathbf{F}$, wild type and $\mathbf{H}$, ipd3-2; $\mathrm{a}=$ arbuscules, $\mathrm{v}=$ vesicles, $\mathrm{h}=$ hyphae, and ih $=$ intraradical hyphae. Scale bars: A to D = 30 $\mu \mathrm{m} ; \mathrm{F}$ to $\mathrm{I}=100 \mu \mathrm{m}$. 
ously demonstrated that the mutation in the autophosphorylated threonine residue (T271D or T271A in M. truncatula in the equivalent position $\mathrm{T} 265 \mathrm{D}$ in $L$. japonicus) results in a gain-of function activity of $\mathrm{CCaMK}$ and spontaneous nodule formation (Gleason et al. 2006; Tirichine et al 2006). Epistatic analysis in L. japonicus using gain-of-function mutations of CCaMK and loss-of-function alleles of symbiotic signaling genes revealed the central regulatory function of CCaMK in the coordination of nodule organogenesis and rhizobial infection (Hayashi et al. 2010; Madsen et al. 2010). IPD3/CYCLOPS interacts with CCaMK and CYCLOPS has been shown to be a target of CCaMK phosphorylation (Messinese et al. 2007; Yano et al. 2008). Thus, IPD3/CYCLOPS appears to function either in a complex with CCaMK or downstream of CCaMK, between perception of calcium oscillations by CCaMK and the activation of the transcription factors NSP1 and NSP2. In addition, the failure of infection in the spontaneous nodules induced by the autoactive form of CCaMK in cyclops mutants indicated the role of CYCLOPS in the CCaMK-mediated cross-signaling from organogenic to the IT pathway (Hayashi et al. 2010; Madsen et al. 2010). Considering this central role for IPD3/CYCLOPS in symbiosis signaling, it is surprising that mutations of IPD3/CYCLOPS do not phenocopy ccamk mutants. Yano and associates (2008) interpreted their data to suggest that $C Y C L O P S$ represents a branch point between nodule organogenesis and bacterial infection, with CYCLOPS functioning only in a pathway leading to bacterial infection. Based on these results, it was suggested that the arrest of infection in the epidermis disturbs the coordination between the infection and organogenic program affecting the progression of nodule organogenesis. However, Capoen and Oldroyd (2008) suggested an alternative explanation, that the IPD3/CCaMK complex is required directly for complete nodule organogenesis and the weak effect of the cyclops mutants on nodule organogenesis may simply be a result of the penetrance of the cyclops mutations. The work described here supports the latter interpretation, because the genetic background significantly impacts the severity of ipd3 mutations. A partial genetic redundancy for IPD3/CYCLOPS function leading to incomplete penetrance of ipd3/cyclops mutations is supported by the differences in effect of ipd 3 in different $M$. truncatula backgrounds, and this may explain why cyclops mutants show less severe phenotypes to ccamk mutants despite both genes functioning at similar positions in symbiosis signaling. This genetic redundancy is not necessarily the result of the action of CYCLOPS homologs but, rather, could be the result of additional proteins phosphorylated by CCaMK.

It was previously found that, in addition to the mutation in the autophosphorylated threonine residue (T271D or T271A), the truncated form of CCaMK containing only the kinase domain (CCaMK 1-311) also results in a gain-of function activity of CCaMK and spontaneous nodule formation (Gleason et al. 2006; Tirichine et al 2006). Although CCaMK 1-311 caused spontaneous nodules, it was not able to complement a ccamk mutant for bacterial infection. In contrast, CCaMK T271D was able to complement ccamk mutants of L. japonicus and $M$. truncatula (Gleason et al. 2006; Hayashi et al. 2010; Tirichine et al 2006), indicating that CCaMK T271D encoded a fully functional gene product. The difference in activity of these two gain-of-function constructs of CCaMK has yet to be explained. Here, we show that CCaMK T271D interacts with IPD3 whereas CCaMK 1-311 failed to interact with IPD3. Therefore, it seems likely that the absence of rhizobial infection in ccamk mutants transformed with CCaMK 1-311 is due to the inability of CCaMK 1-311 to interact with IPD3. We have already suggested that additional genetic components exist that partially compensate for the lack of IPD3/CYCLOPS. Our data suggest that CCaMK 1-311 interacts with these additional genetic factors and, through this activation, induces spontaneous nodulation. In addition, these additional genetic components can compensate the rhizobial and mycorrhizal infection phenotype to some extent, depending on the genetic background. However, rhizobial infection requires the complete action of CCaMK, including the phosphorylation of IPD3/CYCLOPS.

Our work highlights a role for IPD3 in symbiosis signaling. Likely functions for IPD3/CYCLOPS action are the modulation of CCaMK to allow full activity of the protein or the transduction of the signal downstream of CCaMK. The mechanism by which CCaMK activates the transcription factors NSP1 and NSP2 remains unknown. It is likely that IPD3/CYCLOPS allows the appropriate activation of these transcription factors following calcium recognition by CCaMK. This could either be through facilitating CCaMK modification of NSP1/NSP2, direct modulation of these transcription factors by IPD3/CYCLOPS, or the modification of additional components that regulate NSP1/NSP2. Our data imply that alternative mechanisms exist in addition to IPD3/CYCLOPS for the activation of these transcription factors and, ultimately, the promotion of nodule organogenesis and bacterial infection.

\section{MATERIALS AND METHODS}

\section{Plant growth and DNA isolation.}

M. truncatula subsp. truncatula (Jemalong) and M. truncatula subsp. tricycla (R108) genotypes were used as wild-type control for genetic experiments and phenotypic and expression analyses of ipd3-1 and ipd3-2 mutants, respectively. Seed were chemically scarified with sulfuric acid and sterilized as described in the M. truncatula handbook. Sterilized ipd3-1 and wild-type seed were germinated with overnight incubation in darkness at room temperature on inverted agar plates $(0.8 \%$ water agar) following a 4-day-long cold treatment at $4{ }^{\circ} \mathrm{C}$. For phenotypic characterization, wild-type and ipd3-1 mutant plants were grown on square plates containing Gibson (Gibson and Nutman 1960) or buffered nodulation media (BNM) media supplemented with $0.1 \mu \mathrm{M}$ L- $\alpha$-(2-aminoethoxyvinyl)-Gly (AVG) (Sigma-Aldrich, St. Louis) to enhance root growth and nodulation. Plates were placed in growth chambers and kept under photoperiods of $16 \mathrm{~h}$ of light and $8 \mathrm{~h}$ of darkness at 24 and $20^{\circ} \mathrm{C}$, respectively. The seed of R108 and Tnt 1 transposontagged insertion lines were prepared similarly as described above and germinated on agar plates supplemented with $1 \mu \mathrm{M}$ gibberellic acid $\left(\mathrm{GA}_{3}\right)$ at $4{ }^{\circ} \mathrm{C}$ for 2 days followed by overnight incubation at room temperature. Germinated seedlings were further grown on Fahraeus medium.

For genetic mapping, the individuals of the F2 segregating population were grown and characterized for symbiotic phenotype in separate tubes containing Gibson media. F2 plants grown in tubes were placed in growth chambers under the abovedescribed conditions and the symbiotic phenotype was scored 18 to 21 dpi with $S$. meliloti strain B1. The genomic DNA from $M$. truncatula plants was isolated using the ZenoGene40 plant DNA purification kit (Zenon Bio, Szeged, Hungary).

\section{Nodulation, mycorrhization, and GUS assays.}

Four-day-old $M$. truncatula seedlings grown for phenotypic characterization were inoculated with $S$. meliloti 1021 carrying pXLGD4 plasmid (Penmetsa and Cook 1997) expressing the lac $Z$ reporter gene under the control of the hemA promoter. $S$. meliloti strains were grown overnight in liquid TA medium in the presence of streptomycin at $100 \mu \mathrm{g} / \mathrm{ml}$. Bacteria were pelleted and resuspended in liquid Gibson or BNM medium in a final dilution of 1:50. The number of rhizobial microcolonies was counted following lacZ staining and the infected region 
was determined by measuring the root length between the first- and the last-detected infection event. Nodules were sectioned using a Thermo Scientific Microm HM 650V vibration microtome, and histochemical staining for lacZ activity was carried out as reported by Boivin and associates (1990).

For the mycorrhization assay, $G$. intraradices aseptic spores were produced as previously described by St-Arnaud and associates (1996). For each line, 12 2-day-old seedlings were transferred on 1:1 Terragreen (Oil-dri UK Ltd., Wisbech, U.K.) and low-nutrient seed compost (Levington Horticulture Ltd., Ipswich, U.K.) medium, and 250 purified spores per seedling were applied directly to their roots. Six weeks after inoculation, root samples were taken and ink stained following the protocol reported by Vierheilig and associates (1998), with some modifications. Roots were cleared in $10 \% \mathrm{KOH}$ at $95^{\circ} \mathrm{C}$ for $10 \mathrm{~min}$ and then stained for $2.5 \mathrm{~min}$ at $95^{\circ} \mathrm{C}$ in a $5 \%$ ink and $5 \%$ acetic acid solution. Destaining was performed by repeated washes in deionized water. Colonization levels were measured using the gridline intersection method as described by Giovannetti and Mosse (1980). For mycorrhization assays of transposon-tagged mutant and wild-type R108 lines, seedlings were transplanted into pots with sand and Turface and inoculated with 400 sterile $G$. intraradices spores (Premier Tech Biotechnologies, Rivière-du-Loup, Quebec, Canada). Plants were harvested 27 days after inoculation. Roots were washed and cleared with $10 \% \mathrm{KOH}$ at $90^{\circ} \mathrm{C}$ for 10 min. Roots were rinsed with distilled water and stained with $0.01 \%$ (wt/vol) Trypan blue in lactoglycerol.

The ipd3-1 mutant plants were assayed for early nodulin gene expression by histochemical staining for GUS activity. Wild-type plants carrying the pMtENOD $11:: G U S$ construct (Journet et al. 2001) were crossed to ipd3-1 plants to introduce the construct into mutant background. F2 plants carrying the $\mathrm{p} M t E N O D 11:: G U S$ construct and containing the ipd3-1 deletion allele were identified by PCR and selected for multiplication. Wild-type and ipd3-1 (pMtENOD11::GUS) plants were grown on plates of BNM supplemented with $0.1 \mu \mathrm{M}$ AVG to enhance root growth for 7 days. Plants were then transferred into liquid BNM media containing $1 \mathrm{nM} \mathrm{NF}$ and treated for $24 \mathrm{~h}$. Roots were washed with $0.1 \mathrm{M}$ potassium phosphate buffer $(\mathrm{pH} 7.0)$ and immersed and incubated in the dark in staining solution (1 $\mathrm{mM}$ 5-bromo-4-chloro-3-indolyl- $\beta$-D-glucuronic acid, $50 \mathrm{mM}$ sodium phosphate buffer, $0.5 \mathrm{mM}$ potassium ferrocyanide, 0.5 $\mathrm{mM}$ potassium ferricyanide, $20 \%$ methanol, and Triton X-100 at $0.1 \mathrm{ml} / 100 \mathrm{ml}$ ) overnight at $37^{\circ} \mathrm{C}$. After rinsing in phosphate buffer and cleaning in $70 \%$ ethanol, the roots were analyzed and imaged using an Olympus SZX12 stereo microscope.

\section{Identification of novel ipd3 alleles.}

The ipd3-1 mutant was isolated in the same forward genetic screen in which the nin-1 mutant was identified (Marsh et al. 2007). Genetic mapping of the ipd3-1 mutant locus was carried out on an F2 segregating population of the cross of ipd3-1 and A20 M. truncatula lines. The rough map position of the IPD3 locus was determined by analyzing the genotypes of 38 F2 plants determined for a microsatellite core marker set of the M. truncatula genome (Mun et al. 2006). Fine mapping was carried out using an additional $420 \mathrm{~F} 2$ plants and chromosomal walking experiments were done with analyzing the phenotype and genotypes of a subset of F2 individuals preselected with flanking genetic markers ENOD40 and MtB93 (Mun et al. 2006). Genetic markers GTP and BRL identifying polymorphism between A20 and the Jemalong background were used to delimit the region for the IPD3 locus.

Primers of genetic markers GTP and BRL are listed in Supplementary Table S1. PCR amplifications for genetic mapping were carried out at $94^{\circ} \mathrm{C}$ for $30 \mathrm{~s} ; 50,55$, or $60^{\circ} \mathrm{C}$, depending on the primer pairs, for $30 \mathrm{~s}$; and $72^{\circ} \mathrm{C}$ for $1 \mathrm{~min}$ per cycle.
The insertion mutant allele of ipd3 was isolated in a PCRbased screen of a Tnt1-insertional population of M. truncatula based on the R108 genotype (Tadege et al. 2008). The screen was carried out using nested PCR (IPD3 forward primers IPD3-fw1 and IPD3-fw2 with Tnt1-specific primers LTR3 and LTR4) with ExTaq DNA Polymerase (TaKaRa, Shiga, Japan) in deconvoluting DNA pools of 500, 100, and 10 to reach single plants. In all, 1 independent mutant line (NF5939) was selected out of 7,000 independent mutant lines. A PCR-amplified fragment was sequenced to identify the exact insertion site of the 5.3-kb Tntl retrotransposon. PCR analyses were carried out on a segregating population of NF5939 (ipd3-2) to identify homozygous mutants using gene-specific primers IPD3-fw3 and IPD3-rv2 and the Tnt1-specific primer LTR6 (Fig. 3).

\section{Microscopic analysis \\ of nodules and calcium spiking experiments.}

Confocal laser scanning microscopy was performed using an Olympus Fluoview FV1000 confocal laser scanning microscope (Olympus Life Science Europa GmbH, Hamburg, Germany). Microscope configuration was the following: objective lenses, UPLSAPO ×20 (dry, NA:0.75), UPLFLN $\times 40$ (oil, NA:1.3), and UPLSAPO $\times 60$ (oil, NA:1.35); sampling speed, $4 \mu \mathrm{s} /$ pixel; line averaging, $2 \times$; scanning mode, sequential unidirectional; excitation, $488 \mathrm{~nm}$ (SYTO13); laser transmissivity, 5\%; main dichroic beamsplitter, DM405/488; intermediate dichroic beamsplitter, SDM 490; and emission filter, 505 to $530 \mathrm{~nm}$. For fluorescence stereo microscopy, an Olympus SZX12 stereo microscope with $\times 0.5$ and $\times 1$ objectives was used. GFP and DsRed images were captured with the "green" and "red" filter sets, respectively, as follows: GFP: excitation, 460 to $490 \mathrm{~nm}$; dichroic beam splitter, $505 \mathrm{~nm}$, and emission, 510 to $550 \mathrm{~nm}$; and DsRed: excitation, 530 to $560 \mathrm{~nm}$, dichroic beam splitter, $570 \mathrm{~nm}$, and emission, 590 to $650 \mathrm{~nm}$. For bright-field images, a white LED light source (Photonic Optics, Vienna) was used. Photos were captured using an Olympus Camedia C7070 digital camera. Calcium spiking experiments were performed as described by Ding and associates (2008).

\section{Gene expression analyses.}

For real-time qRT-PCR experiments, plants were grown on plates containing BNM medium. Five-day-old A17 and mutant seedlings were inoculated with $S$. meliloti strain 1021 by flooding the roots on plate. Bacteria were pelleted and resuspended in liquid Gibson medium in a final dilution of 1:50 (optical density at $600 \mathrm{~nm}=0.05$ to 0.1 ). For NF treatment, 5-day-old seedlings were transferred into beakers and incubated for $16 \mathrm{~h}$ in liquid BNM medium supplemented with $10 \mathrm{nM}$ NF. For qRT-PCR, roots were harvested and RNA was extracted by TRIzol reagent (Life Technologies Invitrogen, Carlsbad, CA, U.S.A.) following the manufacturer's protocol. The RNA was treated with DNase I, amplification grade (Invitrogen) according to the manufacturer's instructions. RNA were cleaned up by RNeasy Mini Kit (Qiagen Gmbh., Hilden, Germany), then genomic DNA free total RNA was quantified using a spectrophotometer (Nanodrop-1000'; Thermo Fisher Scientific, Inc. NanoDrop Technologies, Wilmington, DE, U.S.A.) and checked for quality by gel electrophoresis. Complementary DNA was prepared from $1 \mu \mathrm{g}$ of total RNA with SuperScript III firststrand synthesis system for RT-PCR (Life Technologies, Gaithersburg, MD, U.S.A.) using oligo-dT primers according to the manufacturer's instructions. Real-time qRT-PCR was performed on a MiniOpticon System (Bio-Rad, Hercules, CA, U.S.A.) using Bio-Rad CFX Manager software 1.5. SYBR Green JumpStart Taq ReadyMix (Sigma-Aldrich) and Maxima SYBR Green Master Mix (Thermo Fisher Scientific, Inc., Fermentas, Vilnius, Lithuania) were used to monitor double- 
stranded DNA synthesis in a 48-well plate, and the final primer concentration of each gene-specific primer was $100 \mathrm{nM}$. The initial denaturation step of $94^{\circ} \mathrm{C}$ for 2 min (JumpStart) or 10 min (Maxima) was followed by 45 to 50 cycles of $94^{\circ} \mathrm{C}$ for 15 $\mathrm{s}, 60^{\circ} \mathrm{C}$ for $20 \mathrm{~s}$, and $72^{\circ} \mathrm{C}$ for $20 \mathrm{~s}$ to perform PCR amplification. After each PCR amplification, melting curves were analyzed to check nonspecific and nonrequired PCR products. Primer-dimer formations were estimated by running control amplifications without cDNA template. Ubiquitin was used as a reference gene and ubiquitin intron for checking genomic DNA contamination in cDNA samples (Kakar et al. 2008). Results were represented as a threshold cycle $\left(C_{T}\right)$ value, which were averaged from three replicate reactions. For normalization, the reference gene $C_{T}$ value was subtracted from the $C_{T}$ value of the gene of interest $\left(\Delta \mathrm{C}_{\mathrm{T}}\right) \cdot \Delta \Delta \mathrm{C}_{\mathrm{T}}$ value was calculated by subtracting $\Delta \mathrm{C}_{\mathrm{T}}$ of the 0 -h (experiments with $\mathrm{NF}$ induction) or 1-dpi (experiments with $S$. meliloti inoculation) sample from the $\Delta \mathrm{C}_{\mathrm{T}}$ value of the samples from other time points. The qRT-PCR analysis was repeated three times with the cDNA mix of three to six independent biological repeats. Fold induction $\left(2^{\Delta \Delta C T)}\right.$ of the repeats were averaged and plotted using SE.

\section{Complementation experiments accomplished by $A$. rhizogenes transformation.}

The complementation of mutant alleles of IPD3 was carried out by generating and testing transgenic hairy roots for nodulation as previously described by Boisson-Dernier and associates (2001). Constructs for complementation experiments were generated with both the $35 \mathrm{~S}$ constitutive promoter and the native promoter of the IPD3 gene using the Gateway cloning technology (Invitrogen). The coding sequence of the IPD3 gene was inserted into vector pK7WG2D (Plant Systems Biology, VIB-Ghent University, Gent, Belgium) to create the construct under the control of the $35 \mathrm{~S}$ promoter. In order to create the construct driven by the native promoter, the $1,233 \mathrm{bp}$ of the promoter region and the $566 \mathrm{bp}$ of the terminal sequence of the IPD3 gene were assembled with IPD3 coding sequence. The promoter and terminal sequences were PCR amplified with the primer pairs of IPD3prom_GWfor/IPD3_R10 and IPD3_F6/ IPD3_3'UTR_Gwrev using Jemalong genomic DNA and the amplified fragments were assembled with the coding sequence of IPD3 using the restriction sites $\mathrm{NcoI}$ in exon 1 and XagI in exon10. The construct was recombined into vector pKGWD,0, (Plant Systems Biology), pK7FWG2-RR (Wang et al. 2010) and pKGW-R (provided by P. Smit; Wageningen University). The constructs were introduced into either the ARqual or MSU440 strain of A. rhizogenes in the case of ipd3-1 and ipd3-2 mutants, respectively, and used for hairy root transformation as described by (Boisson-Dernier et al. 2001). The vectors contained either the GFP or the DsRed reporter gene to identify transgenic hairy roots. Transformed plants were inoculated with S. meliloti 1021 (mutant in Jemalong background) or 2011 (mutant in R108 background) carrying the lacZ marker gene (pXLGD4) following transfer into pouches (Mega International, St. Paul, MN, U.S.A.) or zeolite substrate (Geoproduct Kft., Mád, Hungary), and nodules were stained for LacZ activity similarly to wild-type and mutant nodules after 4 weeks of transferring.

\section{Yeast two-hybrid analysis.}

Yeast two-hybrid analysis was carried out using the Matchmaker GAL4 two-hybrid system 3 (Clontech, Palo Alto, CA, U.S.A.) as described by Messinese and associates (2007). The transformed AH109 yeast strains were selected on synthetic dropout (SD) plates lacking Leu and Trp (LW). The expression of HIS3 or HIS3 and ADE2 reporter genes was assessed by colony growth of yeast strains transformed with the full-length or mutated open reading frame of $C C A M K$ and IPD3 genes on SD-LWH (Leu-, Trp-, and His-) and SD-LWHA (Leu-, Trp-, His-, and Ade-) plates. The liquid $\beta$-galactosidase assay was carried out according to the Yeast Protocols Handbook PT3024-1 (Clontech).

\section{ACKNOWLEDGMENTS}

This work was supported by the Országos Tudományos Kutatási Alap 67576 grant of the Hungarian Research Scientific Fund, the Biotechnology and Biological Sciences Research Council, U.K., the United States Department of Agriculture Cooperative State Research Education and Extension Service grant number 05-562-35319, and by the National Science Foundation (NSF) Plant Genome Program (DBI 0703285). Microscopy performed at the University of Wisconsin-Madison Plant Imaging Center was supported by the NSF (DBI-0421266). We thank I. Szívós and M. Komláti for skillful technical assistance and K. Findlay and S. Bunewell for carrying out sample preparation and transmission electron microscopy imaging at the Department of Cell and Developmental Biology, John Innes Centre.

\section{LITERATURE CITED}

Akiyama, K., Matsuzaki, K., and Hayashi, H. 2005. Plant sesquiterpenes induce hyphal branching in arbuscular mycorrhizal fungi. Nature 435:824-827.

Ané, J. M., Kiss, G. B., Riely, B. K., Penmetsa, R. V., Oldroyd, G. E. D., Ayax, C., Lévy, J., Debellé, F., Baek, J. M., Kaló, P., Rosenberg, C., Roe, B. A., Long, S. R., Dénarié, J., and Cook, D. R. 2004. Medicago truncatula DMI1 required for bacterial and fungal symbioses in legumes. Science 303:1364-1367.

Auriac, M. C., and Timmers, A. C. J. 2007. Nodulation studies in the model legume Medicago truncatula: Advantages of using the constitutive EF1 alpha promoter and limitations in detecting fluorescent reporter proteins in nodule tissues. Mol. Plant-Microbe Interact. 20:10401047.

Benaben, V., Duc, G., Lefebvre, V., and Huguet, T. 1995. TE7, an inefficient symbiotic mutant of Medicago truncatula Gaertn. cv. Jemalong. Plant Physiol. 107:53-62.

Boisson-Dernier, A., Chabaud, M., Garcia, F., Bécard, G., Rosenberg, C., and Barker, D. 2001. Agrobacterium rhizogenes-transformed roots of Medicago truncatula for the study of nitrogen-fixing and endomycorrhizal symbiotic associations. Mol. Plant-Microbe Interact. 14:695-700.

Boivin, C., Camut, S., Malpica, C., Truchet, G., and Rosenberg, C. 1990. Rhizobium meliloti genes encoding catabolism of trigonelline are induced under symbiotic conditions. Plant Cell 2:1157-1170.

Bright, L. J., Liang, Y., Mitchell, D. M., and Harris, J. M. 2005. The LATD gene of Medicago truncatula is required for both nodule and root development. Mol. Plant-Microbe Interact. 18:521-532.

Capoen, W., and Oldroyd, G. 2008. How CYCLOPS keeps an eye on plant symbiosis. Proc. Natl. Acad. Sci. U.S.A. 105:20053-20054.

Capoen, W., Goormachtig, S., De Rycke, R., Schroeyers, K., and Holsters, M. 2005. SrSymRK, a plant receptor essential for symbiosome formation. Proc. Natl. Acad. Sci. U.S.A. 102:10369-10374.

Catoira, R., Galera, C., de Billy, F., Penmetsa, R. V., Journet, E. P., Maillet, F., Rosenberg, C., Cook, D., Gough, C., and Dénarié, J. 2000. Four genes of Medicago truncatula controlling components of a Nod factor transduction pathway. Plant Cell 12:1647-1665.

Combier, J. P., Frugier, F., de Billy, F., Boualem, A., El-Yahyaoui, F., Moreau, S., Vernie, T., Ott, T., Gamas, P., Crespi, M., and Niebel, A. 2006. MtHAP2-1 is a key transcriptional regulator of symbiotic nodule development regulated by microRNA169 in Medicago truncatula. Genes Dev. 20:3084-3088.

Ding, Y. L., Kaló, P., Yendrek, C., Sun, J. H., Liang, Y., Marsh, J. F., Harris, J. M., and Oldroyd, G. E. D. 2008. Abscisic acid coordinates Nod factor and cytokinin signaling during the regulation of nodulation in Medicago truncatula. Plant Cell 20:2681-2695.

Ehrhardt, D. W., Wais, R., and Long, S. R. 1996. Calcium spiking in plant root hairs responding to Rhizobium nodulation signals. Cell 85:673-681.

Endre, G., Kereszt, A., Kevei, Z., Mihacea, S., Kalo, P., and Kiss, G. B. 2002. A receptor kinase gene regulating symbiotic nodule development. Nature 417:962-966.

Felle, H. H., Kondorosi, E., Kondorosi, A., and Schultze, M. 1998. The role of ion fluxes in Nod factor signalling in Medicago sativa. Plant J. 13:455-463.

Gibson, A. H., and Nutman, P. S. 1960. Studies on the physiology of nodule formation. VII. A reappraisal of the effect of preplanting. Ann. Bot 24:420-433. 
Giovannetti, M., and Mosse, B. 1980. Evaluation of techniques for measuring vesicular arbuscular mycorrhizal infection in roots. New Phytol. $84: 489-500$

Gleason, C., Chaudhuri, S., Yang, T. B., Munoz, A., Poovaiah, B. W., and Oldroyd, G. E. D. 2006. Nodulation independent of rhizobia induced by a calcium-activated kinase lacking autoinhibition. Nature 441:11491152 .

Godfroy, O., Debellé, F., Timmers, T., and Rosenberg, C. 2006. A rice calcium- and calmodulin-dependent protein kinase restores nodulation to a legume mutant. Mol. Plant-Microbe Interact. 19:495-501.

Groth, M., Takeda, N., Perry, J., Uchida, H., Draxl, S., Brachmann, A., Sato, S., Tabata, S., Kawaguchi, M., Wang, T. L., and Parniske, M. 2010 NENA, a Lotus japonicus homolog of Sec13, is required for rhizodermal infection by arbuscular mycorrhiza fungi and rhizobia but dispensable for cortical endosymbiotic development. Plant Cell 22:2509-2526.

Hayashi, T., Banba, M., Shimoda, Y., Kouchi, H., Hayashi, M., and Imaizumi-Anraku, H. 2010. A dominant function of CCaMK in intracellular accommodation of bacterial and fungal endosymbionts. Plant $\mathrm{J}$. 63:141-154

Haynes, J., Czymmek, K., Carlson, C., Veereshlingam, H., Dickstein, R., and Sherrier, D. 2004. Rapid analysis of legume root nodule development using confocal microscopy. New Phytol. 163:661-668.

Imaizumi-Anraku, H., Takeda, N., Charpentier, M., Perry, J., Miwa, H., Umehara, Y., Kouchi, H., Murakami, Y., Mulder, L., Vickers, K., Pike, J., Downie, J., Wang, T., Sato, S., Asamizu, E., Tabata, S., Yoshikawa, M., Murooka, Y., Wu, G., Kawaguchi, M., Kawasaki, S., Parniske, M. and Hayashi, M. 2005. Plastid proteins crucial for symbiotic fungal and bacterial entry into plant roots. Nature 433:527-531.

Jones, K. M., Kobayashi, H., Davies, B. W., Taga, M. E., and Walker, G. C. 2007. How rhizobial symbionts invade plants: The SinorhizobiumMedicago model. Nat. Rev. Microbiol. 5:619-633.

Journet, E. P., Pichon, M., Dedieu, A., de Billy, F., Truchet, G., and Barker, D. G. 1994. Rhizobium meliloti Nod factors elicit cell-specific transcription of the ENOD12 gene in transgenic alfalfa. Plant J. 6:241-249.

Journet, E. P., El-Gachtouli, N., Vernoud, V., de Billy, F., Pichon, M., Dedieu, A., Arnould, C., Morandi, D., Barker, D. G., and GianinazziPearson, V. 2001. Medicago truncatula ENOD11: A novel RPRP-encoding early nodulin gene expressed during mycorrhization in arbuscule-containing cells. Mol. Plant-Microbe Interact. 14:737-748.

Kakar, K., Wandrey, M., Czechowski, T., Gaertner, T., Scheible, W., Stitt, M., Torres-Jerez, I., Xiao, Y., Redman, J., Wu, H., Cheung, F., Town, C., and Udvardi, M. 2008. A community resource for high-throughput quantitative RT-PCR analysis of transcription factor gene expression in Medicago truncatula. Plant Methods 4:18. Online publication. doi:10.1186/1746-4811-4-18

Kaló, P., Gleason, C., Edwards, A., Marsh, J., Mitra, R. M., Hirsch, S., Jakab, J., Sims, S., Long, S. R., Rogers, J., Kiss, G. B., Downie, J. A., and Oldroyd, G. E. D. 2005. Nodulation signaling in legumes requires NSP2, a member of the GRAS family of transcriptional regulators. Science 308:1786-1789.

Kanamori, N., Madsen, L. H., Radutoiu, S., Frantescu, M., Quistgaard, E. M. H., Miwa, H., Downie, J.A., James, E.K., Felle, H. H., Haaning, L. L., Jensen, T. H., Sato, S., Nakamura, Y., Tabata, S., Sandal, N., and Stougaard, J. 2006. A nucleoporin is required for induction of Ca2+ spiking in legume nodule development and essential for rhizobial and fungal symbiosis. Proc. Natl. Acad. Sci. U.S.A. 103:359-364.

Kiss, E., Oláh, B., Kaló, P., Morales, M., Heckmann, A., Borbola, A., Lozsa, A., Kontar, K., Middleton, P., Downie, J., Oldroyd, G., and Endre, G. 2009. LIN, a Novel type of U-Box/WD40 protein, controls early infection by rhizobia in legumes. Plant Physiol. 151:1239-1249.

Kosuta, S., Chabaud, M., Lougnon, G., Gough, C., Dénarié, J., Barker, D. G., and Bécard, G. 2003. A diffusible factor from arbuscular mycorrhizal fungi induces symbiosis-specific MtENOD11 expression in roots of Medicago truncatula. Plant Physiol. 131:952-962.

Kosuta, S., Hazledine, S., Sun, J., Miwa, H., Morris, R., Downie, J., and Oldroyd, G. 2008. Differential and chaotic calcium signatures in the symbiosis signaling pathway of legumes. Proc. Natl. Acad. Sci. U.S.A. 105:9823-9828.

Kuhn, H., Kuster, H., and Requena, N. 2010. Membrane steroid-binding protein 1 induced by a diffusible fungal signal is critical for mycorrhization in Medicago truncatula. New Phytol. 185:716-733.

Lévy, J., Bres, C., Geurts, R., Chalhoub, B., Kulikova, O., Duc, G., Journet, E. P., Ané, J. M., Lauber, E., Bisseling, T., Dénarié, J., Rosenberg, C. and Debellé, F. 2004. A putative $\mathrm{Ca}^{2+}$ and calmodulin-dependent protein kinase required for bacterial and fungal symbioses. Science 303:13611364.

Lima, P. T., Faria, V. G., Patraquim, P., Ramos, A. C., Feijo, J. A., and Sucena, E. 2009. Plant-microbe symbioses: New insights into common roots. Bioessays 31:1233-1244.

Limpens, E., Mirabella, R., Fedorova, E., Franken, C., Franssen, H.,
Bisseling, T., and Geurts, R. 2005. Formation of organelle-like N-2-fixing symbiosomes in legume root nodules is controlled by DMI2. Proc. Natl. Acad. Sci. U.S.A. 102:10375-10380

Lodwig, E., and Poole, P. 2003. Metabolism of Rhizobium bacteroids. Crit Rev. Plant Sci. 22:37-78.

Madsen, L. H., Tirichine, L., Jurkiewicz, A., Sullivan, J. T., Heckmann, A. B., Bek, A. S., Ronson, C. W., James, E. K., and Stougaard, J. 2010 The molecular network governing nodule organogenesis and infection in the model legume Lotus japonicus. Nat. Commun. 1:10.

Maillet, F., Poinsot, V., André, Puech-Pagés, V., Haouy, A., Gueunier, M., Cromer, L., Giraudet, D., Formey, D, Niebel, A., Martinez, E. A., Driguez, H., Bécard, G., and Dénarié, D. 2011. Fungal lipochitooligosaccharide symbiotic signals in arbuscular mycorrhiza. Nature 469:5864.

Marsh, J. F., Rakocevic, A., Mitra, R. M., Brocard, L., Sun, J., Eschstruth A., Long, S. R., Schultze, M., Ratet, P., and Oldroyd, G. E. D. 2007. Medicago truncatula NIN is essential for rhizobial-independent nodule organogenesis induced by autoactive calcium/calmodulin-dependent protein kinase. Plant Physiol. 144:324-335.

Maunoury, N., Redondo-Nieto, M., Bourcy, M., Van de Velde, W., Alunni, B., Laporte, P., Durand, P., Agier, N., Marisa, L., Vaubert, D., Delacroix, H., Duc, G., Ratet, P., Aggerbeck, L., Kondorosi, E., and Mergaert, P. 2010. Differentiation of symbiotic cells and endosymbionts in Medicago truncatula nodulation are coupled to two transcriptome-switches. PLOS ONE 5:e9519. doi:10.1371/journal.pone.0009519. Published online.

Messinese, E., Mun, J. H., Yeun, L.H., Jayaraman, D., Rouge, P., Barre, A., Lougnon, G., Schornack, S., Bono, J. J., Cook, D. R., and Ané, J. M. 2007. A novel nuclear protein interacts with the symbiotic DMI3 calcium- and calmodulin-dependent protein kinase of Medicago truncatula. Mol. Plant-Microbe Interact. 20:912-921.

Mitra, R. M., Gleason, C. A., Edwards, A., Hadfield, J., Downie, J. A., Oldroyd, G. E. D., and Long, S. R. 2004. A Ca2+/calmodulin-dependent protein kinase required for symbiotic nodule development: Gene identification by transcript-based cloning. Proc. Natl. Acad. Sci. U.S.A. 101:4701-4705.

Mun, J. H., Kim, D. J., Choi, H. K., Gish, J., Debellé, F., Mudge, J., Denny, R., Endre, G., Saurat, O., Dudez, A. M., Kiss, G. B., Roe, B., Young, N. D., and Cook, D. R. 2006. Distribution of microsatellites in the genome of Medicago truncatula: A resource of genetic markers that integrate genetic and physical maps. Genetics 172:2541-2555.

Navazio, L., Moscatiello, R., Genre, A., Novero, M., Baldan, B., Bonfante, P., and Mariani, P. 2007. A diffusible signal from arbuscular mycorrhizal fungi elicits a transient cytosolic calcium elevation in host plant cells. Plant Physiol. 144:673-681.

Oláh, B., Briére, C., Bécard, G., Dénarié, J., and Gough, C. 2005. Nod factors and a diffusible factor from arbuscular mycorrhizal fungi stimulate lateral root formation in Medicago truncatula via the DMI1/DMI2 signalling pathway. Plant J. 44:195-207.

Oldroyd, G. E. D., and Downie, J. A. 2006. Nuclear calcium changes at the core of symbiosis signalling. Curr. Opin. Plant Biol. 9:351-357.

Oldroyd, G. E. D., and Downie, J. A. 2008. Coordinating nodule morphogenesis with rhizobial infection in legumes. Annu. Rev. Plant Biol. 59:519-546.

Oldroyd, G. E. D., and Long, S. R. 2003. Identification and characterization of nodulation-signaling pathway 2, a gene of Medicago truncatula involved in Nod factor signaling. Plant Physiol. 131:1027-1032.

Ovchinnikova, E., Journet, E. P., Chabaud, M., Cosson, V., Ratet, P., Duc, G., Fedorova, E., Liu, W., Op den Camp, R., Zhukov, V., Tikhonovich, I., Borisov, A., Bisseling, T., and Limpens, E. 2011. IPD3 controls the formation of nitrogen-fixing symbiosomes in pea and Medicago. Mol. Plant Microbe Interact. 24:1333-1344.

Parniske, M. 2004. Molecular genetics of the arbuscular mycorrhizal symbiosis. Curr. Opin. Plant Biol. 7:414-421.

Parniske, M. 2008. Arbuscular mycorrhiza: The mother of plant root endosymbioses. Nat. Rev. Microbiol. 6:763-775.

Penmetsa, R. V., and Cook, D. R. 1997 A legume ethylene-insensitive mutant hyperinfected by its rhizobial symbiont. Science 275:527-530.

Riely, B. K., Mun, J. H., and Ané, J. M. 2006. Unravelling the molecular basis for symbiotic signal transduction in legumes. Mol. Plant Pathol. 7:197-207.

Saito, K., Yoshikawa, M., Yano, K., Miwa, H., Uchida, H., Asamizu, E., Sato, S., Tabata, S., Imaizumi-Anraku, H., Umehara, Y., Kouchi, H., Murooka, Y., Szczyglowski, K., Downie, J., Parniske, M., Hayashi, M., and Kawaguchi, M. 2007. NUCLEOPORIN85 is required for calcium spiking, fungal and bacterial symbioses, and seed production in Lotus japonicus. Plant Cell 19:610-624.

Smith, S. E., Barker, S. J., and Zhu, Y. G. 2006. Fast moves in arbuscular mycorrhizal symbiotic signalling. Trends Plant Sci. 11:369-371.

StArnaud, M., Hamel, C., Vimard, B., Caron, M., and Fortin, J. 1996. En- 
hanced hyphal growth and spore production of the arbuscular mycorrhizal fungus Glomus intraradices in an in vitro system in the absence of host roots. Mycol. Res. 100:328-332.

Stracke, S., Kistner, C., Yoshida, S., Mulder, L., Sato, S., Kaneko, T., Tabata, S., Sandal, N., Stougaard, J., Szczyglowski, K., and Parniske, M. 2002. A plant receptor-like kinase required for both bacterial and fungal symbiosis. Nature 417:959-962.

Tadege, M., Wen, J. Q., He, J., Tu, H. D., Kwak, Y., Eschstruth, A., Cayrel, A., Endre, G., Zhao, P. X., Chabaud, M., Ratet, P., and Mysore, K. S. 2008. Large-scale insertional mutagenesis using the Tnt1 retrotransposon in the model legume Medicago truncatula. Plant J. 54:335-347.

Timmers, A. C. J., Auriac, M. C., and Truchet, G. 1999. Refined analysis of early symbiotic steps of the Rhizobium-Medicago interaction in relationship with microtubular cytoskeleton rearrangements. Development 126:3617-3628

Tirichine, L., James, E. K., Sandal, N., and Stougaard, J. 2006. Spontaneous root-nodule formation in the model legume Lotus japonicus: A novel class of mutants nodulates in the absence of rhizobia. Mol. PlantMicrobe Interact. 19:373-382.

Tirichine, L., Sandal, N., Madsen, L. H., Radutoiu, S., Albrektsen, A. S., Sato, S., Asamizu, E., Tabata, S., and Stougaard, J. 2007. A gain-offunction mutation in a cytokinin receptor triggers spontaneous root nodule organogenesis. Science 315:104-107.
Vierheilig, H., Coughlan, A., Wyss, U., and Piche, Y. 1998. Ink and vinegar, a simple staining technique for arbuscular-mycorrhizal fungi. Appl. Environ. Microbiol. 64:5004-5007.

Wais, R. J., Galera, C., Oldroyd, G., Catoira, R., Penmetsa, R. V., Cook, D., Gough, C., Denarie, J., and Long, S. R. 2000. Genetic analysis of calcium spiking responses in nodulation mutants of Medicago truncatula. Proc. Natl. Acad. Sci. U.S.A. 97:13407-13412.

Wang, B., Yeun, L., Xue, J., Liu, Y., Ané, J. M., and Qiu, Y. 2010. Presence of three mycorrhizal genes in the common ancestor of land plants suggests a key role of mycorrhizas in the colonization of land by plants New Phytol. 186:514-525.

Yano, K., Yoshida, S., Muller, J., Singh, S., Banba, M., Vickers, K., Markmann, K., White, C., Schuller, B., Sato, S., Asamizu, E., Tabata, S., Murooka, Y., Perry, J., Wang, T., Kawaguchi, M., Imaizumi-Anraku, H., Hayashi, M., and Parniske, M. 2008. CYCLOPS, a mediator of symbiotic intracellular accommodation. Proc. Natl. Acad. Sci. U.S.A. 105:20540-20545.

\section{AUTHOR-RECOMMENDED INTERNET RESOURCE}

Noble Foundation M. truncatula Handbook: www.noble.org/MedicagoHandbook 